\title{
Regional Differences in the Structure of Juglans nigra Phytobiome Reflect Geographical Differences in Thousand Cankers Disease Severity
}

\author{
Aaron J. Onufrak, ${ }^{1}$ Geoffrey M. Williams, ${ }^{2}$ William E. Klingeman III, ${ }^{3}$ Melissa A. Cregger, ${ }^{4,5}$ Dawn M. Klingeman, ${ }^{4}$ \\ Jennifer M. DeBruyn, ${ }^{6}$ Matthew D. Ginzel, ${ }^{2,7}$ and Denita Hadziabdic ${ }^{1, \dagger}$ \\ ${ }^{1}$ Department of Entomology and Plant Pathology, University of Tennessee, Knoxville, TN 37996 \\ ${ }^{2}$ Department of Forestry and Natural Resources, Purdue University, West Lafayette, IN 47907 \\ ${ }^{3}$ Department of Plant Sciences, University of Tennessee, Knoxville, TN 37996 \\ ${ }^{4}$ Biosciences Division, Oak Ridge National Laboratory, Oak Ridge, TN 37831 \\ ${ }^{5}$ Department of Ecology and Evolutionary Biology, University of Tennessee, Knoxville, TN 37996 \\ ${ }^{6}$ Department of Biosystems Engineering and Soil Science, University of Tennessee, Knoxville, TN 37996 \\ ${ }^{7}$ Department of Entomology, Purdue University, West Lafayette, IN 47907
}

Accepted for publication 28 July 2020.

\section{ABSTRACT}

Thousand cankers disease threatens Juglans nigra (Eastern Black Walnut) in urban and natural landscapes. Incidence and severity of thousand cankers disease is higher in the host's introduced range in the western United States. We hypothesized that these differences are driven partly by geographical variation in the host phytobiome due to its roles in host stress tolerance, nutrient acquisition, and defense. To evaluate the role of the phytobiome in mediating thousand cankers disease, we characterized the $J$. nigra phytobiome of diseased and healthy trees in portions of its native (Indiana and Tennessee) and introduced (Washington) ranges. Grafted clones present in each state and open-pollinated populations were sampled. DNA was extracted from soil and branch (caulosphere) tissues and internal transcribed spacer and 16s regions were sequenced for characterization of fungal and bacterial communities. We found that microbial communities in the caulosphere and soil differ between native and introduced ranges of
J. nigra and harbor different mutualistic and pathogenic microorganisms. Additionally, caulosphere microbial communities were more species rich and diverse in the native range of $J$. nigra, suggesting greater levels of functional redundancy and multifunctionality in the native-range phytobiome compared with the introduced range. We also found higher network complexity in the caulosphere of trees in the introduced range and evidence for two alternative stable community states associated with diseased and healthy trees. Our results provide support for the hypothesis that geographical variation in thousand cankers disease incidence and severity is partially driven by differences in the phytobiome of $J$. nigra in its introduced and native ranges.

Keywords: biotic resistance hypothesis, ecology, endophytes, fungal and bacterial communities, metagenomics, microbiome, mutualism, network complexity, soil ecology, thousand cankers disease

${ }^{\dagger}$ Corresponding author: D. Hadziabdic; dhadziab@utk.edu

A. J. Onufrak and G. M. Williams are co-first authors who provided equal contributions.

Funding: This work was supported, in part, by the Fred M. Van Eck Forestry Foundation, The University of Tennessee AgResearch Funding, University of Tennessee's Open Publishing Support Fund, the University of Tennessee AgResearch Doctoral Scholarship Program, the Department of Entomology and Plant Pathology, and the United States Department of Agriculture National Institute of Food and Agriculture (NIFA) (Hatch project 1009630: TEN00495). Additional funding support for co-authors M. Cregger and D. Klingeman was provided by the U.S. Department of Energy Genomic Science Program, Office of Science, Biological and Environmental Research, as part of the Plant Microbe Interfaces Scientific Focus Area at ORNL (https://pmi.ornl.gov).

*The $e$-Xtra logo stands for "electronic extra" and indicates that supplementary figures and supplementary tables are published online.

The author(s) declare no conflict of interest.
Thousand cankers disease (TCD) threatens the ecological and economic sustainability of walnut trees in urban and natural landscapes (Feeley 2010; Treiman and Tuttle 2009; Treiman et al. 2010). TCD is caused by the fungal pathogen Geosmithia morbida M. Kolařík, Freeland, C. Utley \& Tisserat (Ascomycota: Hypocreales: Bionectriaceae) and its insect vector, the walnut twig beetle (WTB; Pityophthorus juglandis Blackman; Coleoptera: Curculionidae: Scolytinae). Susceptible hosts include Juglans spp. and Pterocarya spp., important for nut and timber production. The most susceptible host species is Juglans nigra L. (Eastern Black Walnut), which is native to most of the central and eastern United States (Utley et al. 2013; Williams 1990). Both the insect vector and fungal pathogen appear to have originated from the arid southwestern United States and Mexico and have been detected in 18 U.S. states, including 7 states within the native range of J. nigra, 
and Italy (Bright 1981; Hadziabdic et al. 2014a; Juzwik et al. 2015, 2016; Moore et al. 2019; Moricca et al. 2019; Rugman-Jones et al. 2015; Wood and Bright 1992; Zerillo et al. 2014).

Incidence and severity of TCD appears to be greatest in the western United States, where J. nigra has been introduced, and widespread decline and massive die-offs have occurred (Tisserat et al. 2009). However, within the native range of J. nigra, TCD has been detected in isolated locations (Hadziabdic et al. 2014b; Juzwik et al. 2015, 2016; Oren et al. 2018; Williams 1990). In the native range, there appear to be two disease outcomes of TCD in J. nigra: either tree recovery following initial decline, or gradual decline in health and eventual tree mortality (Griffin 2015; Seybold et al. 2019). These geographical patterns of TCD incidence and severity may be a consequence of less favorable climatic conditions for disease establishment in the eastern United States. For instance, reduced WTB activity and abundance in the eastern United States are hypothesized to result from higher levels of precipitation that reduce drought stress on host trees and susceptibility to WTB (Griffin 2015; Seybold et al. 2019). Host genetics may also influence susceptibility of J. nigra to TCD (Blood et al. 2018; Utley et al. 2013).

In addition to the influence of abiotic factors and host genetics, absence of mutualists in the phytobiome of J. nigra in its introduced range or presence of microbial antagonists of G. morbida in the native range may affect TCD severity (Gazis et al. 2018). Phytobiome composition is largely influenced by host genetics and the physicochemical environment in which plants grow (Bálint et al. 2013; Cregger et al. 2018; Erlandson et al. 2018; Ren et al. 2019; Veach et al. 2019). The phytobiome is known to influence the health of introduced plants (Gundale et al. 2016; Hoffman and Arnold 2008; Klironomos 2002; Zhang et al. 2010). Introduced plants can benefit by escaping pathogens and predators from their native ranges, thereby facilitating establishment, range expansion, and invasiveness (van der Putten et al. 2007). Conversely, organisms introduced into novel habitats, including plants, pests, and pathogens, may lose mutualists or encounter novel pathogens or parasites that limit range expansion (Parker et al. 2006; Prider et al. 2008; Stricker et al. 2016; Thompson et al. 2019). In support of this hypothesis, culture-dependent comparison of Juglans spp. microbiomes microbiome between the eastern and western United States found greater abundance of potential TCD antagonists (Trichoderma spp.) in the native range and potential novel pathogens (Sporothrix spp. (=Ophiostoma)) in the invaded range (Gazis et al. 2018).

To compare the phytobiomes of diseased versus healthy and native versus introduced J. nigra, we chose locations in Indiana, Tennessee, and Washington, where TCD severity and incidence varied across each study area, and tested trees for the presence of G. morbida with a molecular probe (Oren et al. 2018). We used DNA sequencing methods to characterize bacterial and fungal community composition of J. nigra in both the native and introduced ranges of the species. We predicted that the phytobiome of $J$. nigra in its native range would have higher $\alpha$-diversity and differ in composition compared with the introduced range in the western United States, and that phytobiome composition would vary with host genetics. Fungal functional guild, indicator species, and microbial network analyses were used to identify microorganisms associated with disease and geography, and to evaluate the extent to which the presence and absence of mutualists and diseaseassociated microorganisms differs between the native and introduced ranges.

\section{MATERIALS AND METHODS}

Study sites, TCD pressure, and tree sources. Study areas were selected in Indiana (Tippecanoe County) and Tennessee (Polk and
Knox Counties) to represent the northern and southern native ranges of $J$. nigra. An additional study area in Walla Walla County, WA, where disease pressure was high and trees were in early to advanced stages of TCD-related decline, was included to represent $J$. nigra in its introduced range in the western United States.

In Walla Walla, WA, active populations of WTB were detected at both sites as early as 2009 and crown decline is present throughout the county (Zerillo et al. 2014). To date, there has been no record of WTB or G. morbida in Tippecanoe County, IN. In Tennessee, we sampled from Knox County, a quarantined area where TCD was widespread throughout urban areas and G. morbida was detected, and Polk County, a buffer zone where the transport of walnut products outside of the county is limited and WTB were present at low levels but G. morbida was not detected (Grant et al. 2011; Griffin 2015; Oren et al. 2018) (https://www.tn.gov/) (W. E. Klingeman and D. Hadziabdic, unpublished data). Tippecanoe County, IN soils were silt loam and loamy sand Alfisols; Polk County, TN soils were loam Entisols; Knox County, TN soils were Ultisols; and Walla Walla County, WA soils were silt loam Mollisols.

At sites in each state, three grafted clonal trees were selected from the same four scion stock accessions (HTIRC numbers 55, 130, 132, and 272), which originated from a Hardwood Tree Improvement and Regeneration Center (HTIRC) program that is jointly administered by the U.S. Forest Service Northern Research Station and Purdue University (https://www.htirc.org). Grafted clones from each of the four genotypes had been established in each state. Additionally, nongrafted, wild-type (WT) trees were sampled from nearby border areas in Washington, Indiana, TCD-positive Knox County, and TCD-negative Polk County. GPS coordinates, planting dates, and number of clones and WT trees at each location are presented in Table 1.

Sample collection methodology. All samples were collected between April and June 2017. From each tree, we collected samples from branches (henceforth, the caulosphere) and bulk soil with sterile tools. For the caulosphere microbiome, two to four branches (approximately $6 \mathrm{~cm}$ in diameter) were collected per tree from different cardinal directions. Branches were sectioned into $30 \mathrm{~cm}$ segments, placed into large plastic zipper-seal bags, transported to the laboratory on ice, and stored in a walk-in cooler at $4^{\circ} \mathrm{C}$ for 1 to 4 days until drill shavings could be collected. Drill shavings were taken following Oren et al. (2018), and stored at $-80^{\circ} \mathrm{C}$ until DNA extraction.

For soil microbiome samples, leaf litter and debris were removed from the tree base. A 2-cm-diameter stainless steel auger was used to collect a total of eight $20-\mathrm{cm}$ soil cores from four cardinal directions at distances of 20 and $30 \mathrm{~cm}$ from the base of each tree. All eight cores were pooled by tree and homogenized in the field in paper bags. Coarse debris (e.g., large roots, rocks, and so on) was removed by hand from the pooled sample, labeled, and split into subsamples for soil analysis and DNA extraction. For laboratory DNA extraction, an approximately 10-g subsample was taken from each pooled and homogenized soil sample, immediately placed in liquid nitrogen, and stored at $-80^{\circ} \mathrm{C}$ until further processing. The remaining soil was bulked and stored at $4^{\circ} \mathrm{C}$. Soil was air dried, ground, passed through a 2-mm sieve (number 10), and sent to Brookside Laboratories (New Bremen, OH, U.S.A.) for analysis of $\mathrm{pH}(1: 1)$, soil organic matter (SOM; loss on ignition $360^{\circ} \mathrm{C}$ ), nitrate $\left(\mathrm{NO}_{3} \cdot \mathrm{N}\right)$, ammonium $\left(\mathrm{NH}_{4} \cdot \mathrm{N}\right)$, and Mehlich III extractable aluminum (Al), boron (B), calcium $(\mathrm{Ca})$, copper $(\mathrm{Cu})$, iron $(\mathrm{Fe})$, potassium $(\mathrm{K})$, magnesium $(\mathrm{Mg})$, manganese $(\mathrm{Mn})$, sodium $(\mathrm{Na})$, phosphorus (P), sulfur (S), and zinc (Zn), and total cation exchange capacity (TEC) using standard methods. 
DNA extraction and molecular probe detection of $G$. morbida. We extracted DNA from branch drill shavings following the Qiagen DNA Stool Mini Kit protocol (Qiagen, Germantown, MD, U.S.A.). DNA was extracted from soil by homogenizing approximately $0.25 \mathrm{~g}$ of field-moist soil in a Bead Mill 25 Homogenizer (Omni International, Kennesaw, GA, U.S.A.) and using the DNeasy Powerlyzer Powersoil Kit protocol (Qiagen). The TCD infection status of sampled trees was tested in triplicate following the protocol of Oren et al. (2018).

Amplicon library preparation and sequencing. Internal transcribed spacer (ITS) 1 and ITS2 regions of the fungal ITS were amplified from DNA isolated from drill shavings and sequenced at the University of Tennessee Genomics Core (Knoxville, TN, U.S.A.). The V4 region of the 16s ribosomal RNA (rRNA) for bacteria and archaea was amplified from DNA isolated from drill shavings, and sequenced at Oak Ridge National Laboratory (ORNL; Oak Ridge, TN, U.S.A.). DNA isolated from bulk soil was amplified for fungal ITS1, ITS2, and 16s V4 regions and sequenced at ORNL. To maximize coverage of fungal taxa, the ITS1 region was amplified using the ITS1 and ITS2 primer pair and the ITS2 region was amplified using a pool of six ITS3 and two ITS4 primers (Cregger et al. 2018; White et al. 1990). For amplification of the 16s V4 rRNA region, a pool of four $515 \mathrm{~F}$ and one $806 \mathrm{R}$ primers were used to maximize coverage of bacterial taxa (Cregger et al. 2018).

Amplicon metagenomic sequencing libraries were prepared as described in the Illumina 16s metagenomic sequencing library preparation guide (Part 15044223 Rev B). Pooled libraries were validated on an Agilent Bioanalyzer (Agilent, Santa Clara, CA, U.S.A.) using a DNA7500 chip, and the final library pool concentration was determined on an Invitrogen Qubit (Waltham, MA, U.S.A.) with the broad-range double-stranded DNA assay. A paired-end sequencing run ( 2 by 251 by 8 by 8 ) was completed on an Illumina MiSeq instrument (Illumina, San Diego, CA, U.S.A.) using v2 chemistry. Raw amplicon sequences are located under the NCBI SRA BioProject PRJNA633586.

Sequence processing. The resulting $16 \mathrm{~s}$ and ITS reads were processed in mothur v.1.42.3 (Schloss 2020). Processing of 16s reads followed the mothur MiSeq SOP (Kozich et al. 2013) (https:// mothur.org/wiki/miseq_sop/). We assigned taxonomy to $16 \mathrm{~s}$ sequences using the naïve-Bayesian classifier trained on the SILVA r.132 reference files with an $80 \%$ confidence cut-off. Sequences that either did not classify or were classified as eukaryotes, mitochondria, or chloroplasts were removed. Additionally, sequences classified as bacteria or archaea with unknown phylum designations were also removed prior to operational taxonomic unit (OTU) clustering. Sequences were then clustered into OTUs using a $97 \%$ similarity threshold using the cluster function. Taxonomy was then assigned to the resulting OTUs using the SILVA r.132 database as reference.

Bulk soil and caulosphere ITS reads were processed separately following a modified version of the mothur MiSeq SOP (Kozich et al. 2013) (https://mothur.org/wiki/miseq_sop/). Only ITS2 contigs were used for analysis. Short $(<50 \mathrm{bp})$ or long ( $>450 \mathrm{bp})$ sequences and sequences with homopolymers ( $>10 \mathrm{bp}$ ) were removed. Remaining sequences were preclustered with a maximumdifferences cut-off of $2 \mathrm{bp}$. Taxonomic assignments were made using the UNITE database v.8.0 (Nilsson et al. 2019) (https:// unite.ut.ee). ITS2 amplicons of plant origin or unknown phylum designation were removed and distances were calculated from pairwise alignments prior to OTU clustering at $98 \%$ sequence similarity following Tedersoo et al. (2014), which assessed global variation in soil fungal communities. All code related to sequence processing and analysis are available in an online repository (https:// github.com/readingradio/Juglans.microbiome.github).

Classification of fungal functional guilds. Fungal OTUs were assigned to fungal functional guilds using the online version of the FUNGuild database (http://www.funguild.org/) (Nguyen et al. 2016) with a confidence cutoff of "possible". Abundance values for any OTU assigned to multiple functional guilds were divided by the number of functional guilds assigned so that each possible function for that OTU were equally weighted. To visualize differences in potential fungal functions between states, stacked bar plots depicting the relative abundance of each fungal functional guild were created for each state.

Statistical analyses. All statistical analyses were conducted in $\mathrm{R}$ v.3.4.4 or R v.3.6.0 and packages ape, car, stats, and vegan (Fox et al. 2018; Oksanen et al. 2019; Paradis and Schliep 2019; R Core Team 2018, 2019). To visualize differences in soil physicochemical properties between states, soil physicochemical properties were scaled and centered and a principal component analysis (PCA) was

TABLE 1

Description of field sites and locations of 47 Juglans nigra trees used in this study

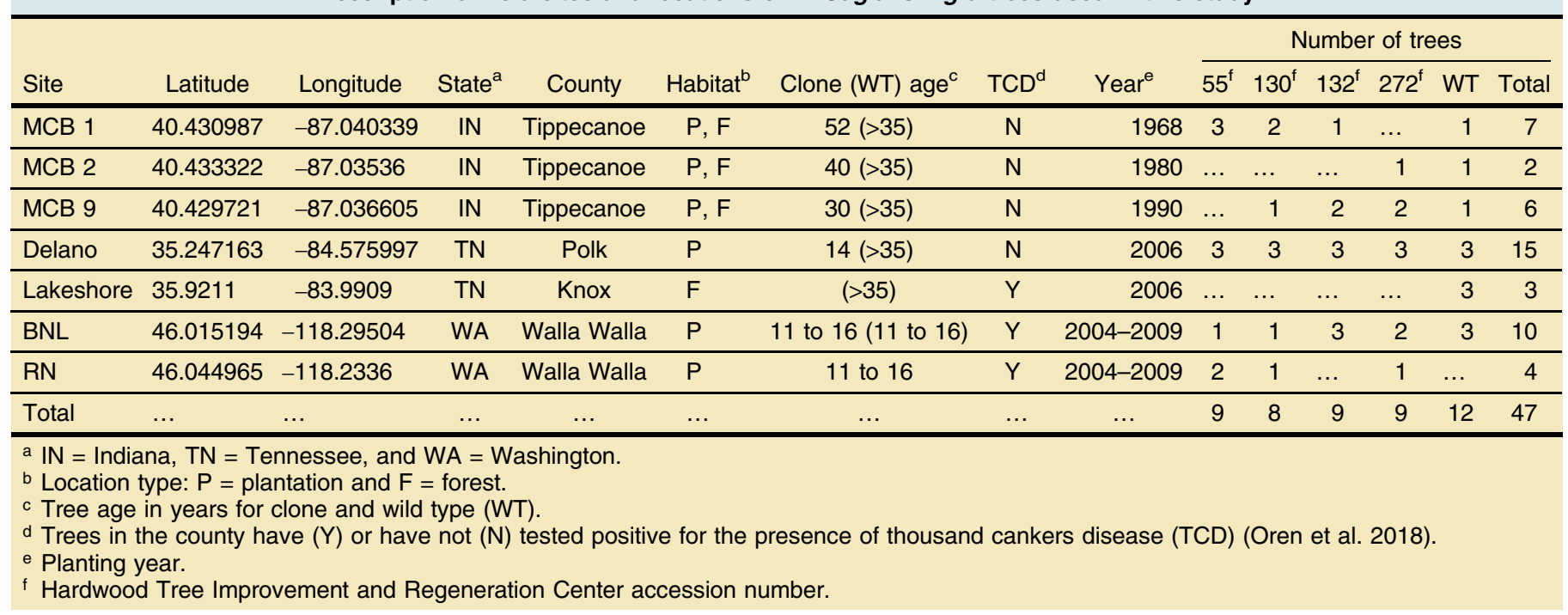


conducted using the prcomp function. The contribution of state to variation in soil physicochemical properties was evaluated using permutational analysis of variance (PERMANOVA) with 10,000 permutations using the adonis function.

OTU abundances were then rarified based on visual inspection of rarefaction curves and Good's coverage values (Supplementary Fig. S1; Supplementary Tables S1 to S4). We calculated the observed species richness and the Shannon diversity index with the specnumber and diversity functions. Singleton OTUs were then removed from rarefied OTU tables prior to construction of stacked bar plots and $\beta$-diversity analysis. We performed a principal coordinate analysis on Bray-Curtis distances for each habitat using the pcoa and vegdist functions.

To test for regional and clonal differences in fungal and bacterial diversity and richness, we performed analyses of variance (ANOVA) with type III sum of squares. Additionally, the contribution of state and clone identity to variation in community composition was tested using PERMANOVA with the adonis function with 10,000 permutations. If there was not a significant interaction $(P>0.05)$, a two-way ANOVA or PERMANOVA was performed with state and clone. For nonsignificant main effects $(P>$ $0.05)$, we report $P$ values from the simplest two-way ANOVA or PERMANOVA that includes the nonsignificant terms. For significant main effects $(P<0.05)$ we report the $P$ value from the ANOVA that only included significant variables. We followed up ANOVA tests with post hoc Tukey tests to identify pairwise differences between states when variables were significant in the ANOVA.

To assess regional differences in beneficial and pathogenic fungal functional groups from FUNGuild (Nguyen et al. 2016), we also performed $\alpha$ - and $\beta$-diversity comparisons for fungal OTUs classified as mycoparasites, plant pathogens, and wood saprotrophs in the caulosphere and OTUs classified as arbuscular mycorrhizae, mycoparasites, or plant pathogens in bulk soils.

Indicator species analysis. To identify archaeal or bacterial and fungal OTUs characteristic of the native and introduced ranges, we performed indicator species analyses for caulosphere and soil communities using the multipatt function from the indicspecies package with 10,000 permutations (De Caceres et al. 2020). We report significant indicator OTUs $(P \leq 0.05$, indicator value $\geq 0.80$ ) for Indiana, Tennessee, Washington, and the Indiana + Tennessee grouping that represents the native range of J. nigra. To identify OTUs characteristic of TCD infection, we also performed indicator analysis to identify fungal and bacterial OTUs in the caulosphere and soil characteristic of TCD-positive and TCDnegative trees.

Network analysis of hub taxa and network complexity. We used network analysis modified from Agler et al. (2016) and Barberán et al. (2012) to (i) compare measures of network complexity between states and (ii) identify "hub taxa" OTUs from merged bacterial and fungal data. OTUs that occurred in less than four caulosphere samples or less than five times in fewer than five soil samples were removed to reduce noise in the dataset from rare taxa. Within each state, Spearman correlation networks were created for absolute value of $R>0.6$ or 0.8 and $P$ cutoffs of $5 \times 10^{-2}$, $10^{-2}, 5 \times 10^{-3}$, and $10^{-3}$ for caulosphere networks, or three orders of magnitude smaller for the much larger soil networks.

The following measures of network complexity were calculated for each state and tissue type at each combination of $R$ and $P$ cutoffs: Kolmogorov-Chaitin algorithmic complexity (Soler-Toscano et al. 2014; Zenil et al. 2014, 2015); entropy sensu Mowshowitz (1968), graph index complexity (Kim and Wilhelm 2008), and normalized edge complexity (Bonchev and Buck 2005) as implemented in the $\mathrm{R}$ package $Q u A C N$ (Mueller et al. 2011); and first- and second-order
Shannon complexity as implemented in the R package acss (Gauvrit et al. 2016). To control for network size (number of OTUs) when comparing relative network complexity among states, we randomly pruned network adjacency matrices to the size of the smallest microbiome network at each $P$ and $R$ cutoff value (i.e., Indiana, Tennessee, or Washington). Bootstrap mean and standard deviation for each complexity measure were then calculated from 20 random submatrices.

Each node in the unpruned networks was analyzed by calculating degree, defined as the number of direct connections to other nodes, and betweenness, which is the proportion of all pairwise node paths that include a node, using the R package tidygraph (Pedersen 2019). After fitting a Weibull function to the degree distribution and an exponential distribution function to the betweenness centrality in each network, we considered to be hub taxa those OTUs that were in the 90th percentile for both degree and betweenness at a given combination of $P$ and $R$ cutoffs.

\section{RESULTS}

Regional differences in soil physicochemical properties. Soil physicochemical properties significantly differed by state (Supplementary Fig. S2) (Pseudo- $\left.F_{2,44}=7.0, P<0.001, R^{2}=0.24\right)$. Following PCA, three principal components (PCs) were retained that accounted for $74 \%$ of the variation observed within the data. Soil physicochemical properties were largely differentiated by state along PC1, whereas variation within states was accounted for more by PC2 (Supplementary Fig. S2). PC1 (39.8\% variation explained) correlated positively with $\mathrm{Al}$ and $\mathrm{Fe}$ and negatively with $\mathrm{B}, \mathrm{Ca}, \mathrm{K}$, $\mathrm{Mg}, \mathrm{Na}, \mathrm{pH}$, and TEC. PC1 also correlated positively with sites in Tennessee and negatively with sites in Washington. PC2 $(20.0 \%$ variation explained) correlated positively with $\mathrm{Ca}, \mathrm{Cu}, \mathrm{Mn}, \mathrm{Zn}$, and $\mathrm{NO}_{3} . \mathrm{N}$ and negatively with $\mathrm{P}$. PC3 (14.3\% variation explained) correlated with $\mathrm{Al}, \mathrm{Fe}, \mathrm{Mg}, \mathrm{Mn}, \mathrm{S}, \mathrm{NH}_{4} \cdot \mathrm{N}, \mathrm{pH}$, and SOM.

Bacterial sequence processing. In total, 2.5 million $16 \mathrm{~s}$ soil sequences and 5 million $16 \mathrm{~s}$ caulosphere sequences were assembled from paired-end reads to characterize the walnut archaeal-bacterial community. Following sequence processing in mothur, 2.3 million 16 s sequences were clustered into 37,604 OTUs in bulk soils and 333,951 sequences were clustered into 4,530 bacterial OTUs in caulosphere samples. In the caulosphere, no archaeal sequences were retained following sequence processing. Prior to downstream analyses for bacterial-archaeal communities, soil 16s samples were rarefied to 37,329 sequences per library with no sample loss; caulosphere $16 \mathrm{~s}$ samples were rarified to 2,000 sequences, from which three samples from Tennessee and four samples from Washington were removed from further analyses. Following rarefaction and singleton removal, caulosphere samples retained a total of 1,791 bacterial OTUs and soil samples retained 21,464 archaealbacterial OTUs.

Fungal sequence processing. For fungal communities within the phytobiome, 308,000 sequences were assembled from the ITS1 region and 2.5 million sequences were assembled from the ITS2 region for soil samples. In the separate Illumina run for caulosphere samples, 1.6 million paired-end reads were assembled from the ITS1 region and 2.9 million paired-end reads were assembled from the ITS2 region. Following processing in mothur, 1.8 million ITS2 sequences clustered into 12,337 OTUs in soils and 629,829 sequences clustered into 4,646 OTUs in the caulosphere. Prior to downstream analyses for fungal communities, soil ITS2 data were rarefied to 25,000 paired-end reads per sample, resulting in the removal of two Washington samples from further analyses. Caulosphere ITS2 data were rarified to 3,400 paired-end reads per sample, resulting in the removal of one sample from Indiana from 
the analyses. Following rarefaction and singleton removal, caulosphere samples retained 1,578 fungal OTUs and soil samples retained 6,738 fungal OTUs.

G. morbida detection. Of the $47 \mathrm{~J}$. nigra trees included in the study, 8 tested positive for G. morbida DNA using the GS004 microsatellite locus. All G. morbida positive samples were from Washington sites. Additionally, Otu0115, the only Geosmithia sp. OTU retained in the data set following rarefaction and singleton removal, was detected in the caulosphere of seven of the same eight trees that tested positive with GS004 markers, except WA_BNL 23_WT. No trees from Indiana or Tennessee tested positive for G. morbida using the GS004 microsatellite locus or contained Otu0115.

Regional and host genetic differences in $\alpha$-diversity measures. In both the caulosphere and bulk soil, fungal and bacterial richness and diversity significantly differed by state (Table 2). In the caulosphere, bacterial richness and diversity was the highest in Indiana and lowest in Washington (Fig. 1A and B; Table 2). In soils, the richness and diversity of archaeal-bacterial communities was highest in Washington and lower in Indiana and Tennessee (Fig. 1C and D; Table 2). For caulosphere fungal communities, richness and diversity was highest in Tennessee and lower in Indiana and Washington (Fig. 1E and F; Table 2). In soils, fungal community richness was higher in Indiana and Tennessee and lowest in Washington (Fig. 1G; Table 2). Soil fungal diversity did not significantly differ between states (Fig. 1H; Table 2). Clone and state-clone interactions were nonsignificant; however, stateclone interaction had a marginally significant effect on fungal richness in the caulosphere (Table 2).

Regional and host genetic differences in microbiome composition. In both the caulosphere and bulk soil, fungal and bacterial community composition differed by state (Fig. 2; Table 2).
Clone identity only had a significant influence on the composition of caulosphere fungal communities (Fig. 2C; Table 2). The majority of $16 \mathrm{~s}$ sequences recovered from caulosphere samples were identified as Proteobacteria, which comprised $45 \%$ of recovered sequences in Indiana, $48 \%$ in Tennessee, and 62\% in Washington (Supplementary Fig. S3). At the class level, the majority of $16 \mathrm{~s}$ caulosphere sequences in Indiana and Tennessee were classified as $\alpha$-Proteobacteria (Proteobacteria), which comprised 32\% of detected sequences in Indiana and 33\% in Tennessee (Fig. 3A). In Washington, the majority of 16 s sequences were identified as $\gamma$ Proteobacteria (Proteobacteria), which comprised 27\% of detected sequences at the class level (Fig. 3A). The dominance of $\gamma$-Proteobacteria in the Washington caulosphere was driven, in part, by $15 \%$ of 16 s sequences in Washington being classified to the Burkholderiaceae ( $\beta$-Proteobacteriales) at the family level, which had less representation in Indiana (3\%) and Tennessee (1\%) (Supplementary Figs. S4A and S5).

In soils, the majority of $16 \mathrm{~s}$ sequences were identified as Proteobacteria from all three states and comprised $24 \%$ of detected sequences in Indiana and Tennessee and $28 \%$ in Washington (Supplementary Fig. S3B). At the class level, $\alpha$-Proteobacteria (Proteobacteria) comprised the greatest proportion of soil 16s sequences recovered from Tennessee and Washington soils, representing $12 \%$ of recovered sequences at the class level in both states. In Indiana, the majority of soil 16s sequences were identified as Nitrososphaeria (Thaumarchaeota), representing $12 \%$ of recovered soil 16 s sequences at the class level (Fig. 3B).

In the caulosphere, the majority of ITS sequences originated from Ascomycota in all three states, representing $96 \%$ of recovered ITS2 sequences in Indiana, 98\% in Tennessee, and 93\% in Washington (Supplementary Fig. S3C). In the caulosphere, the classes

TABLE 2

Results of statistical tests comparing $\alpha$ - and $\beta$-diversity of the Juglans nigra microbiome ${ }^{a}$

\begin{tabular}{|c|c|c|c|c|c|c|c|c|c|c|c|c|c|c|c|c|}
\hline \multirow{3}{*}{$\begin{array}{l}\text { Habitat, organism, } \\
\text { analysis }\end{array}$} & \multicolumn{6}{|c|}{ Richness } & \multicolumn{6}{|c|}{ Shannon diversity } & \multirow{2}{*}{\multicolumn{4}{|c|}{$\begin{array}{c}\beta \text {-Diversity } \\
\text { PERMANOVA }\end{array}$}} \\
\hline & \multicolumn{3}{|c|}{ ANOVA } & \multicolumn{3}{|c|}{ Tukey's HSD $P$ value } & \multicolumn{3}{|c|}{ ANOVA } & \multicolumn{3}{|c|}{ Tukey's HSD $P$ value } & & & & \\
\hline & $F$ & $d f$ & $P$ & TN-IN & WA-IN & WA-TN & $F$ & $d f$ & $P$ & TN-IN & WA-IN & WA-TN & $F^{\mathrm{b}}$ & $d f$ & $P$ & $\overline{R^{2}}$ \\
\hline \multicolumn{17}{|l|}{ Caulosphere } \\
\hline \multicolumn{17}{|l|}{ Fungi } \\
\hline State & 58.6 & 2,43 & $<0.001$ & $<0.001$ & $<0.001$ & $<0.001$ & 18.5 & 2,43 & $<0.001$ & 0.580 & $<0.001$ & $<0.001$ & $21.2^{\mathrm{C}}$ & 2,31 & $<0.001$ & 0.46 \\
\hline Clone & 0.9 & 4,39 & 0.470 & $\ldots$ & $\ldots$ & $\ldots$ & 1.6 & 4,39 & 0.205 & $\ldots$ & $\ldots$ & $\ldots$ & $2.0^{c}$ & 4,31 & 0.006 & 0.09 \\
\hline State $\times$ clone & 2.0 & 8,31 & 0.079 & $\ldots$ & $\ldots$ & $\bar{c}$ & 0.6 & 8,31 & 0.757 & $\ldots$ & $\ldots$ & $\ldots$ & $1.5^{\mathrm{c}}$ & 8,31 & 0.03 & 0.13 \\
\hline \multicolumn{17}{|l|}{ Bacteria } \\
\hline State & 132.6 & 2,37 & $<0.001$ & $<0.001$ & $<0.001$ & $<0.001$ & 35.2 & 2,37 & $<0.001$ & $<0.001$ & $<0.001$ & $<0.001$ & 12.2 & 2,37 & $<0.001$ & 0.40 \\
\hline Clone & 2.3 & 4,33 & 0.080 & $\ldots$ & $\ldots$ & $\ldots$ & 1.0 & 4,33 & 0.414 & $\ldots$ & $\ldots$ & $\ldots$ & 1.4 & 4,33 & 0.090 & 0.09 \\
\hline State $\times$ clone & 1.6 & 8,25 & 0.184 & $\ldots$ & $\ldots$ & $\ldots$ & 0.9 & 8,25 & 0.510 & $\ldots$ & $\ldots$ & $\ldots$ & 1.2 & 8,25 & 0.109 & 0.15 \\
\hline \multicolumn{17}{|l|}{ Soil } \\
\hline \multicolumn{17}{|l|}{ Fungi } \\
\hline State & 8.3 & 2,42 & 0.001 & 0.941 & 0.002 & 0.003 & 0.2 & 2,42 & 0.790 & 0.918 & 0.777 & 0.939 & 6.2 & 2,42 & $<0.001$ & 0.23 \\
\hline Clone & 1.0 & 4,38 & 0.438 & $\ldots$ & $\ldots$ & $\ldots$ & 0.3 & 4,38 & 0.848 & $\ldots$ & $\ldots$ & $\ldots$ & 1.0 & 4,38 & 0.406 & 0.07 \\
\hline State $\times$ clone & 0.6 & 8,30 & 0.802 & $\ldots$ & $\ldots$ & $\ldots$ & 0.8 & 8,30 & 0.602 & $\ldots$ & $\ldots$ & $\ldots$ & 1.0 & 8,30 & 0.466 & 0.15 \\
\hline \multicolumn{17}{|l|}{ Bacteria } \\
\hline State & 14.6 & 2,44 & $<0.001$ & 0.557 & $<0.001$ & $<0.001$ & 26.7 & 2,44 & $<0.001$ & 0.462 & $<0.001$ & $<0.001$ & 9.5 & 2,44 & $<0.001$ & 0.30 \\
\hline Clone & 0.1 & 4,40 & 0.971 & $\ldots$ & $\cdots$ & $\ldots$ & 0.7 & 4,40 & 0.630 & $\ldots$ & $\ldots$ & $\ldots$ & 0.7 & 4,40 & 0.893 & 0.04 \\
\hline State $\times$ clone & 0.5 & 8,32 & 0.860 & $\ldots$ & $\cdots$ & $\ldots$ & 0.4 & 8,32 & 0.910 & $\ldots$ & $\ldots$ & $\ldots$ & 0.7 & 8,32 & 0.938 & 0.10 \\
\hline $\begin{array}{l}\text { a Unless otherw } \\
\text { nonsignificant } \\
\text { HSD = honest } \\
\text { b Pseudo-F stat } \\
\text { c Results for sta }\end{array}$ & $\begin{array}{l}\text { indic } \\
\text { fects } f \\
\text { signifi } \\
\text { ic. } \\
\text {, clon }\end{array}$ & $\begin{array}{l}\text { ated, sic } \\
\text { or clone } \\
\text { sant dif } \\
\text {, and }\end{array}$ & $\begin{array}{l}\text { ificant } \\
\text { vere te } \\
\text { rence, } \\
\text { e state }\end{array}$ & $\begin{array}{l}\text { ain effe } \\
\text { d in a } \\
\text { RMAI }\end{array}$ & $\begin{array}{l}\text { s (signi } \\
\text { nintera } \\
\text { OVA }=p \\
\text { raction }\end{array}$ & $\begin{array}{l}\text { ant } P \text { ve } \\
\text { ive two- } \\
\text { rmutatic } \\
\text { resente }\end{array}$ & $\begin{array}{l}\text { ues in } \\
\text { ay AI } \\
\text { al anc }\end{array}$ & $\begin{array}{l}\text { old) } f \\
\text { OVA, } \\
\text { /sis }\end{array}$ & $\begin{array}{l}\text { rstate w } \\
\text { nd nons } \\
\text { varianc }\end{array}$ & $\begin{array}{l}\text { re teste } \\
\text { gnifican } \\
\mathrm{TN}=\end{array}$ & $\begin{array}{l}\text { using a } \\
\text { hteract } \\
\text { nnesse }\end{array}$ & $\begin{array}{l}\text { רe-wa) } \\
\text { is wer } \\
\text { IN = I }\end{array}$ & alys & r & $\begin{array}{l}\text { ce }(A) \\
\text { D-way } \\
\text { Wast }\end{array}$ & $\begin{array}{l}\text { VA), } \\
\text { iodel. } \\
\text { gton. }\end{array}$ \\
\hline
\end{tabular}


Dothidiomycetes (Ascomycota) and Eurotiomycetes (Ascomycota) dominated the fungal sequences recovered, with Dothidiomycetes being more abundant in Washington (58\%), Eurotiomycetes more abundant in Indiana (50\%), and Tennessee intermediate for both Dothidiomycetes (41\%) and Eurotiomycetes (27\%) (Fig. 3C).

Finally, the majority of soil ITS sequences recovered from soils were identified to the phylum Ascomycota in Indiana (73\%), Tennessee $(74 \%)$, and Washington (76\%) (Supplementary Fig. S3D). Sordariomycetes comprised the greatest proportion of ITS sequences from soil in all three states, representing $32 \%$ of recovered ITS sequences in Indiana, 31\% in Tennessee, and 29\% in Washington (Fig. 3D).

Regional and host genetic differences in fungal functional guilds. In caulosphere fungal communities, 632 of 1,578 OTUs were assigned to a fungal functional guild. The majority of caulosphere fungal sequences belonging to classifiable OTUs were classified as plant pathogens in Indiana (27\%) and Tennessee $(23 \%)$ and as undefined saprotrophs in Washington (29\%) (Fig. 4A). The richness and composition of caulosphere mycoparasite, plant pathogen, and wood saprotroph communities significantly differed between states (Fig. 4C to E; Table 3). Mycoparasite richness was highest in Indiana and Tennessee and lowest in Washington; and wood saprotroph richness was highest in Indiana, followed by Tennessee and Washington (Supplementary Fig. S6A and E; Table 3). Plant pathogen richness was highest in Tennessee and lowest in Washington (Supplementary Fig. S6C; Table 3), with a greater number of potential plant pathogen OTUs from the classes

clone $-130 \quad \oplus 132 \quad * \quad 272 \quad$ \ $55 \quad \square \quad$ WT
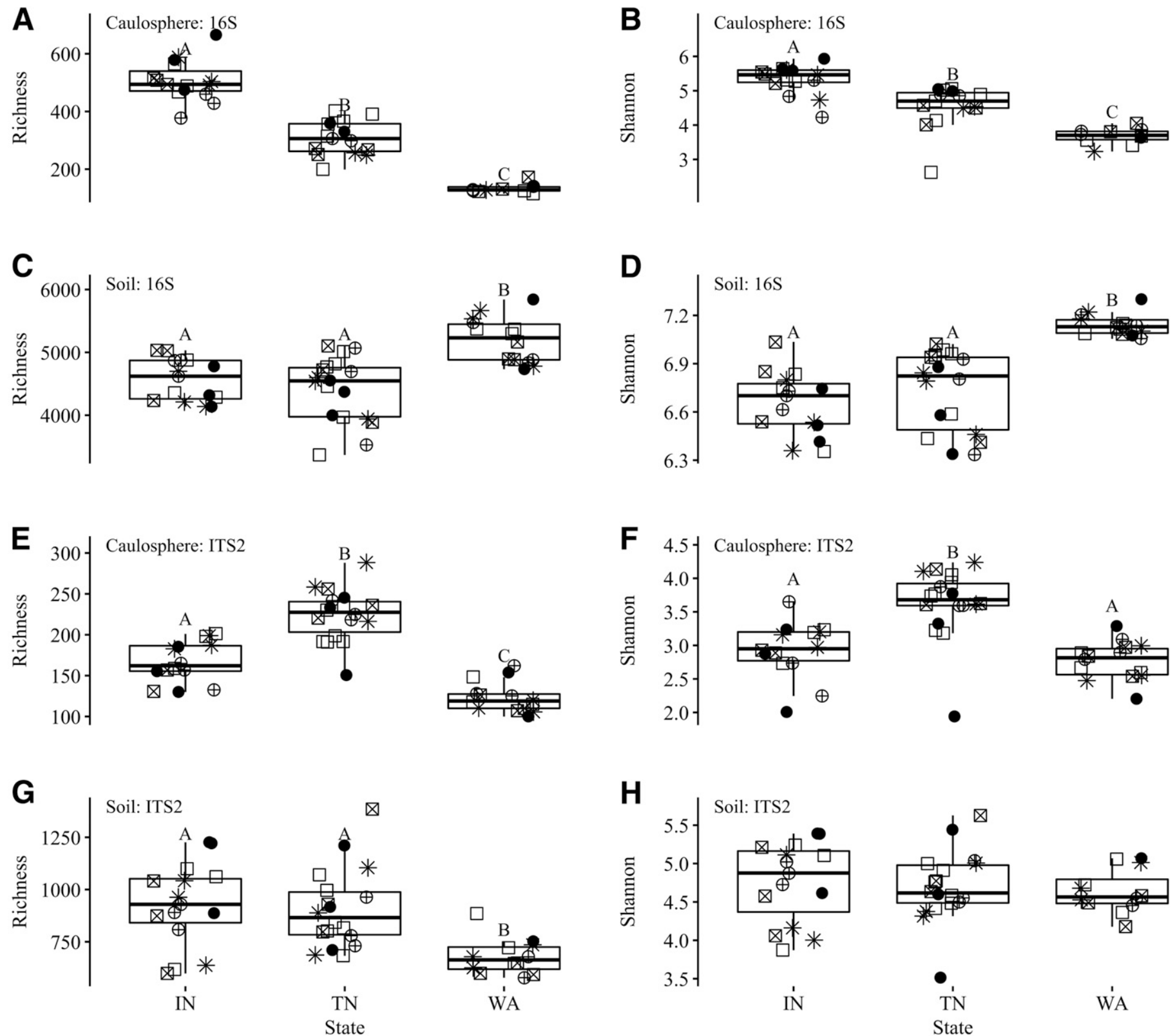

Fig. 1. A, C, E, and G, Observed richness and B, D, F, and H, Shannon Diversity in Juglans nigra trees from Indiana (IN), Tennessee (TN), and Washington (WA) representing caulosphere bacterial communities (A and B), soil bacterial and archaeal communities (C and $D)$, caulosphere fungal communities ( $E$ and $F)$, and soil fungal communities ( $G$ and $H)$. ITS = internal transcribed spacer. Letters represent significant mean differences between states based on Tukey's post hoc comparison $(P<0.05)$. Points are shaped by clone identity. 
Dothidiomycetes (e.g., Helminthosporium spp.), Sordariomycetes (e.g., Diaporthe and Phaeoacremonium spp.), and Eurotiomycetes (e.g., Calciopsis and Strelitziana spp.) in Tennessee. There was also a significant host genetic effect on plant pathogen community composition in the caulosphere (Table 3).

In soil fungal communities, 3,836 of 6,738 OTUs were assigned to a fungal functional guild. The majority of soil fungal sequences belonging to classifiable OTUs were classified as undefined saprotrophs in Indiana (28\%), Tennessee (30\%), and Washington (31\%) (Fig. 4B). Soil arbuscular mycorrhizae, mycoparasites, and plant pathogen richness and community composition significantly differed between states (Fig. 4F to H; Table 3). The richness of arbuscular mycorrhizae and soil plant pathogens was highest in Indiana and
Tennessee and lowest in Washington, and mycoparasite richness was highest in Indiana and lowest in Washington (Supplementary Fig. S6B, D, and F; Table 3).

Indicator species analysis. For bacterial communities in the caulosphere, 175 bacterial indicator OTUs were detected across the four potential state groupings of Indiana (47 OTUs), Tennessee (16 OTUs), Washington (23 OTUs), and Indiana + Tennessee (89 OTUs) (Supplementary Table S5). In soils, in total, 448 bacterial indicator OTUs were detected across the four potential state groupings of Indiana (62 OTUs), Tennessee (60 OTUs), Washington (210 OTUs), and Indiana + Tennessee (116 OTUs). Spirosomaceae and Gemmataceae were common indicator OTUs in the caulosphere and soils, respectively for Indiana, Tennessee, Indiana + Tennessee, and TCDnegative trees in Washington (Fig. 5A; Supplementary Table S5).

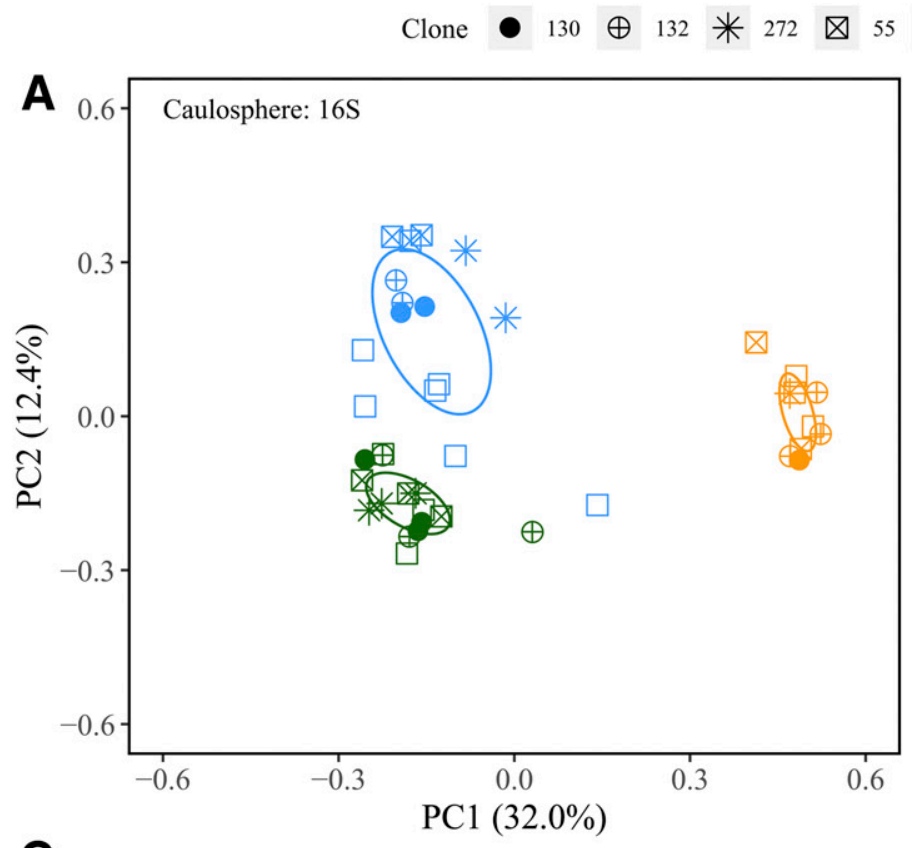

$\square$ WT State - IN - TN - WA
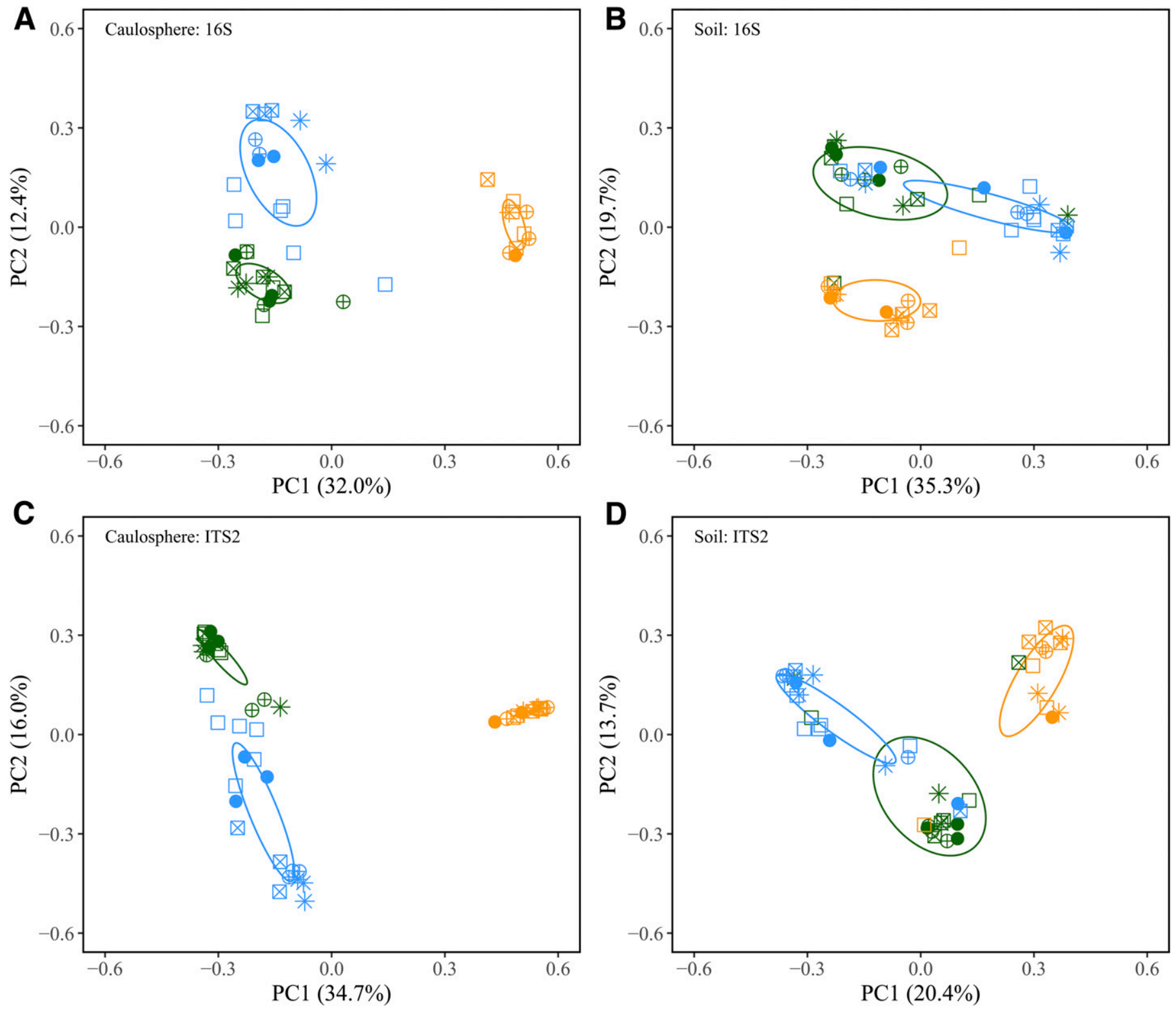

Fig. 2. Principal coordinate (PC) analysis of $\mathbf{A}$ and $\mathbf{C}$, caulosphere and $\mathbf{B}$ and $\mathbf{D}$, soil bacterial and archaeal $(A$ and $B)$ and fungal $(C$ and $D)$ communities from Juglans nigra trees in Indiana (IN), Tennessee (TN), and Washington (WA). Points and ellipses are colored by state and shaped by clone genotype. Ellipses represent standard deviation of axis scores from the group centroid. 
For caulosphere fungal communities, 135 fungal indicator OTUs were detected across the four potential state groupings of Indiana (19 OTUs), Tennessee (43 OTUs), Washington (55 OTUs), and Indiana + Tennessee (18 OTUs) (Supplementary Table S7). In the soil, in total, 198 indicator OTUs were detected across the four potential state groupings Indiana (17 OTUs), Tennessee (42 OTUs), Washington (80 OTUs), and Indiana + Tennessee (59 OTUs) (Supplementary Table S8). Indiana and Tennessee indicator OTUs included many species of Pleosporales (Dothidiomycetes), Phaeomoniellales, and Rhinocladiella (Eurotiomycetes) in caulospheres and entomopathogenic Metarhizium spp. (Sordariomycetes) in soils (Fig. 5B; Supplementary Fig. S8; Supplementary Table S8). Washington had several plant-pathogenic indicator OTUs in the caulosphere such as Cryptococcus cuniculi (Tremellomycetes), Taphrina spp. (Taphrinomycetes), Aureobasidium pullulans, and Alternaria spp. (Dothidiomycetes); and in soils, including Fusarium spp. (Sordariomycetes) and Alternaria spp. (Dothidiomycetes) (Fig. 5B; Supplementary Fig. S8; Supplementary Tables S7 and S8). In Washington, there were nine fungal indicator OTUs of TCD-positive trees, including fungal pathogens such as Alternaria metachromatica, and six fungal indicator OTUs of TCD-negative trees (Fig. 5B), including species of Orbiliaceae, which were also detected in Indiana and Indiana + Tennessee (Fig. 5B).

Network analysis of hub taxa and network complexity. In the caulosphere, Tennessee and Indiana networks contained two subnetworks. Network analysis detected 174 hub caulosphere OTUs across Indiana (84 OTUs), Tennessee (67 OTUs), and Washington (23 OTUs) (Fig. 6A to C; Supplementary Table S9). There were common hub OTUs across all three states (Fig. 6A to C; Supplementary Fig. S9). Hub OTUs from Washington included the black yeast Knufia spp. (FOtu0118) and a bacterium classified to Xanthomonadaceae (BOtu0007), a bacterial family containing plant pathogens known to infect walnut (Arrieta et al. 2010). BOtu0007 was also identified as an indicator OTU of TCD-positive trees in Washington (Figs. 5A and 7). In soils, network analysis detected 185 hub soil OTUs across Indiana (55 OTUs), Tennessee (60 OTUs), and Washington (70 OTUs) (Fig. 6D to F; Supplementary Table S10). There was overlap in soil hub OTUs between all three states (Supplementary Fig. S10).

Overall, in the caulosphere, bootstrap mean microbiome network complexity was highest in Washington, followed by Tennessee and Indiana across all $P$ and $R$ cutoffs for all network complexity measurements (Supplementary Fig. S11). In soils, bootstrap mean microbiome network complexity was highest in Tennessee, followed by Indiana and Washington for all measures and $P$ and $R$ cutoffs, with the sole exception of Mowshowitz entropy, which was lowest in Indiana for $P>10^{-2}$ (Supplementary Fig. S12).

\section{DISCUSSION}

Our study revealed differences in the diversity and composition of the phytobiome within and between the native (i.e., Indiana and Tennessee) and introduced (Washington) ranges of J. nigra, an economically and ecologically important tree species. These results support our central hypothesis of regional differences in the host phytobiome across native and introduced ranges. Furthermore,
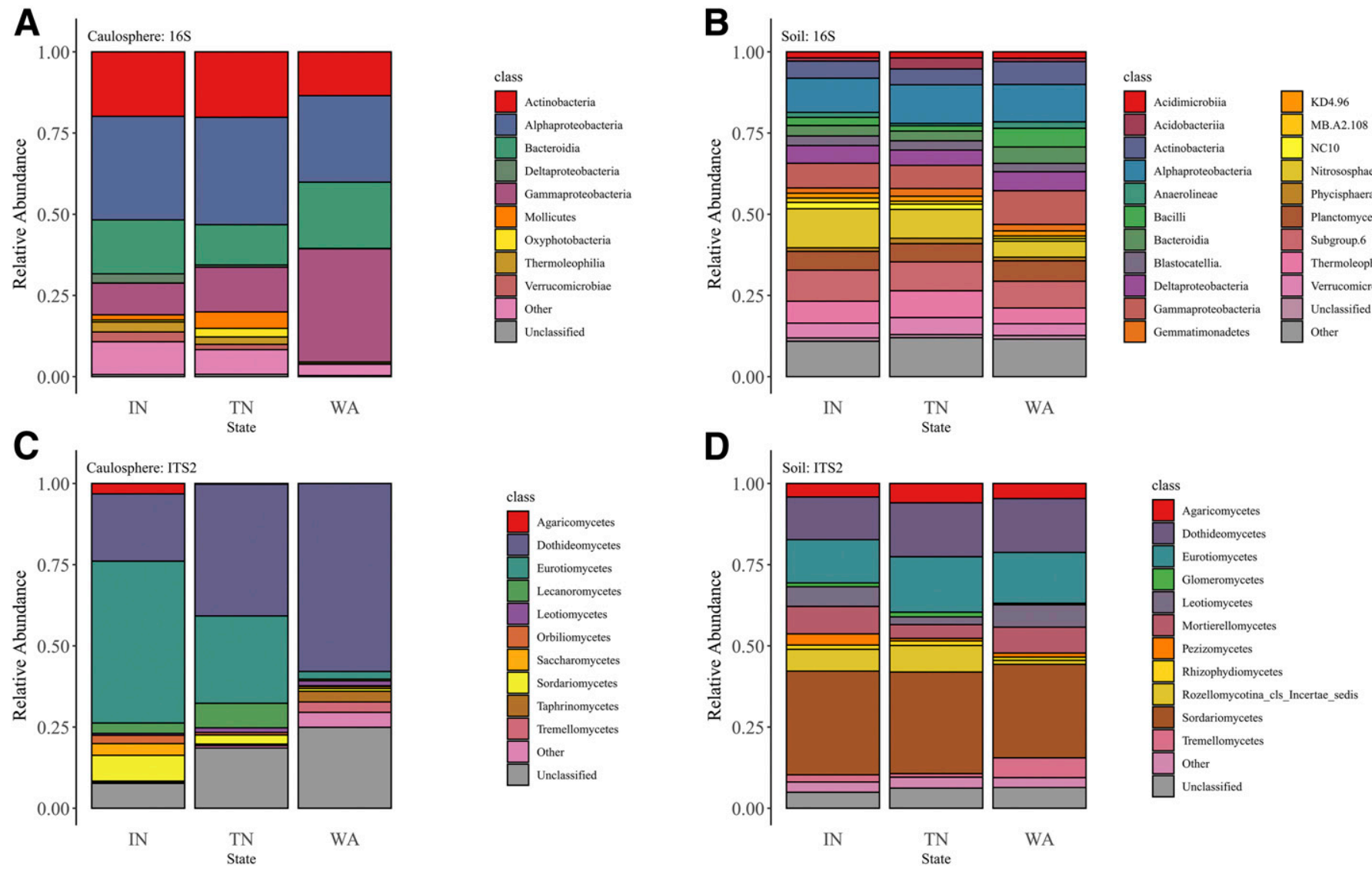

Fig. 3. Relative abundance of $\mathbf{A}$ and $\mathbf{C}$, caulosphere and $\mathbf{B}$ and $\mathbf{D}$, soil bacterial and archaeal $(A$ and $B)$ and fungal $(C$ and $D)$ classes from Juglans nigra trees in Indiana (IN), Tennessee (TN), and Washington (WA). "Other" represents classes that comprised less than $1 \%$ of all bacterial and archaeal sequences or fungal sequences in the study and "Unclassified" represents operational taxonomic units classified at the phylum level but not at the class level. 
$\alpha$-diversity measures were generally lower in Washington compared with the native range, potentially linking observed geographic dependency of TCD incidence and severity to a species-poor phytobiome in the introduced range. We also observed stronger geographical differences in the $\alpha$ - and $\beta$-diversity of the caulosphere compared with bulk soil.

Fungal and bacterial communities in the caulosphere of J. nigra within the introduced range had lower species richness and diversity when compared with trees from the native range. This finding is congruent with previous studies that observed differences in the $\alpha$-diversity of microbial communities between the native and introduced ranges of plant hosts (Gundale et al. 2016; Lu-Irving et al. 2019). We cannot rule out the possibility that lower species richness and patterns of $\beta$-diversity observed in Washington caulosphere samples were partly a consequence of TCD infection because all eight TCD-positive trees were located in Washington. The microbiome of diseased plants can have lower levels of $\alpha$-diversity compared with healthy plants (Koskella et al. 2017; Trivedi et al. 2012; Wei et al. 2018).

Although it is possible that Washington caulosphere communities were less diverse as a consequence of infection, our data support the hypothesis that the higher levels of $\alpha$-diversity recorded from Indiana and Tennessee caulospheres compared with the introduced range (Washington) could potentially function to limit establishment success, severity, and spread of G. morbida in the native range of $J$. nigra. Despite the fact that network analysis distinguished distinct microbial communities associated with trees that tested positive and negative for G. morbida in Washington, overall $\alpha$ - and $\beta$-diversity of Washington samples differed dramatically from the native range. Although detected in eastern Tennessee, TCD has not spread very far since its initial detection in 2009 (Tisserat et al. 2009). Apart from the incidental recovery of an adult WTB at a sawmill, no WTB have been detected in Indiana. Moreover, state-wide surveys have found no evidence of TCD in standing trees, despite the recovery of G. morbida from other beetle species (Juzwik et al. 2015; Marshall 2015; Seybold et al. 2019).

At local scales, diverse communities are often more resistant to invasion than species-poor communities (i.e., biotic resistance hypothesis) due to limited resource availability and niche space (Fitzgerald et al. 2016; Knops et al. 1999; Pinto and Ortega 2016; Stachowicz et al. 1999; van Elsas et al. 2012). In contrast, several studies have found a positive relationship between $\alpha$-diversity and
A

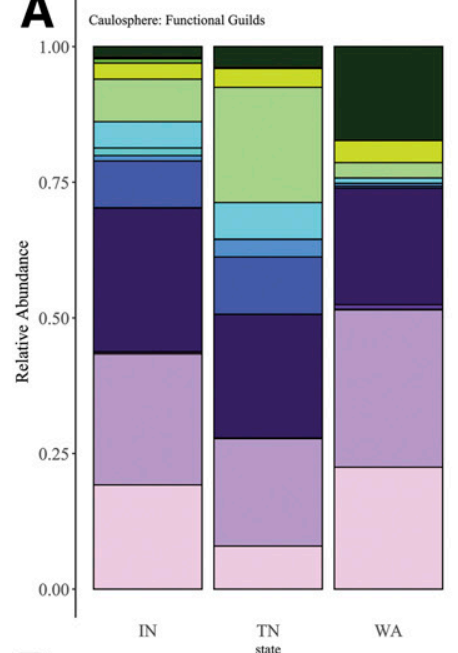

B

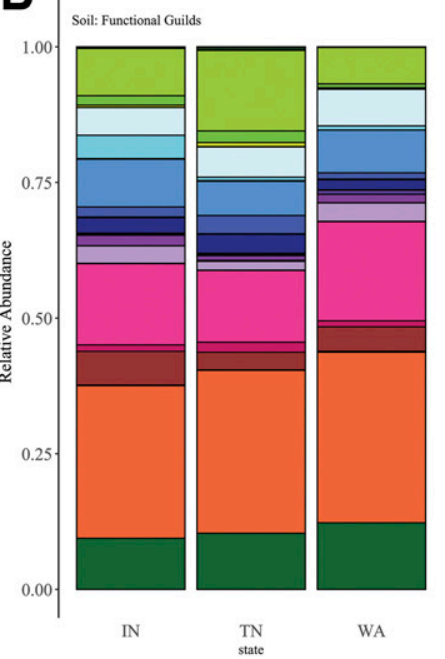

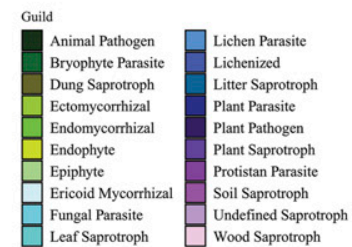

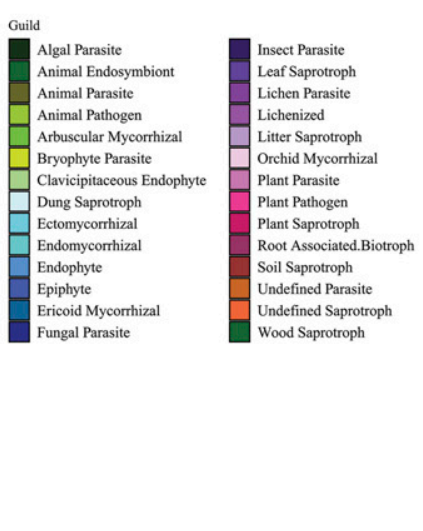

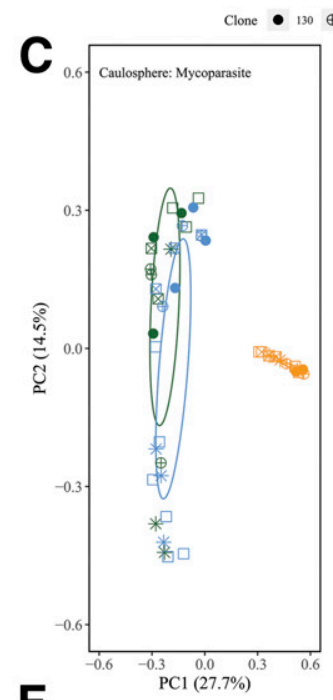

$\mathbf{F}$

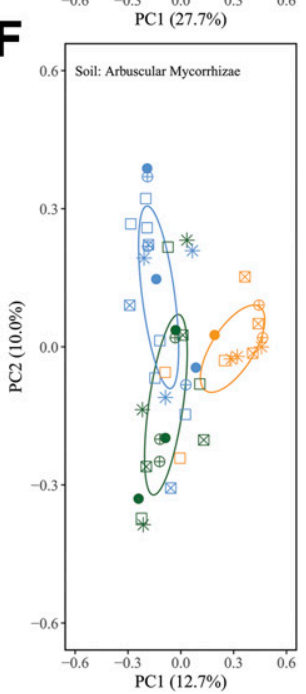

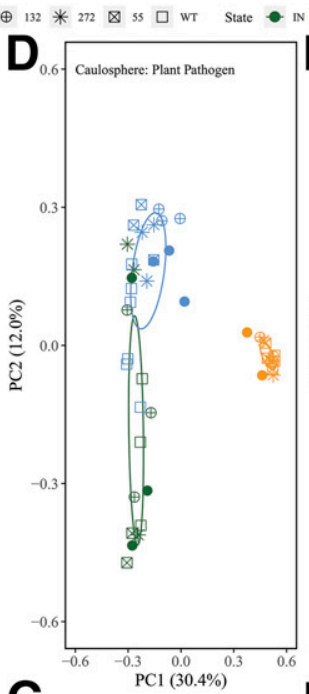
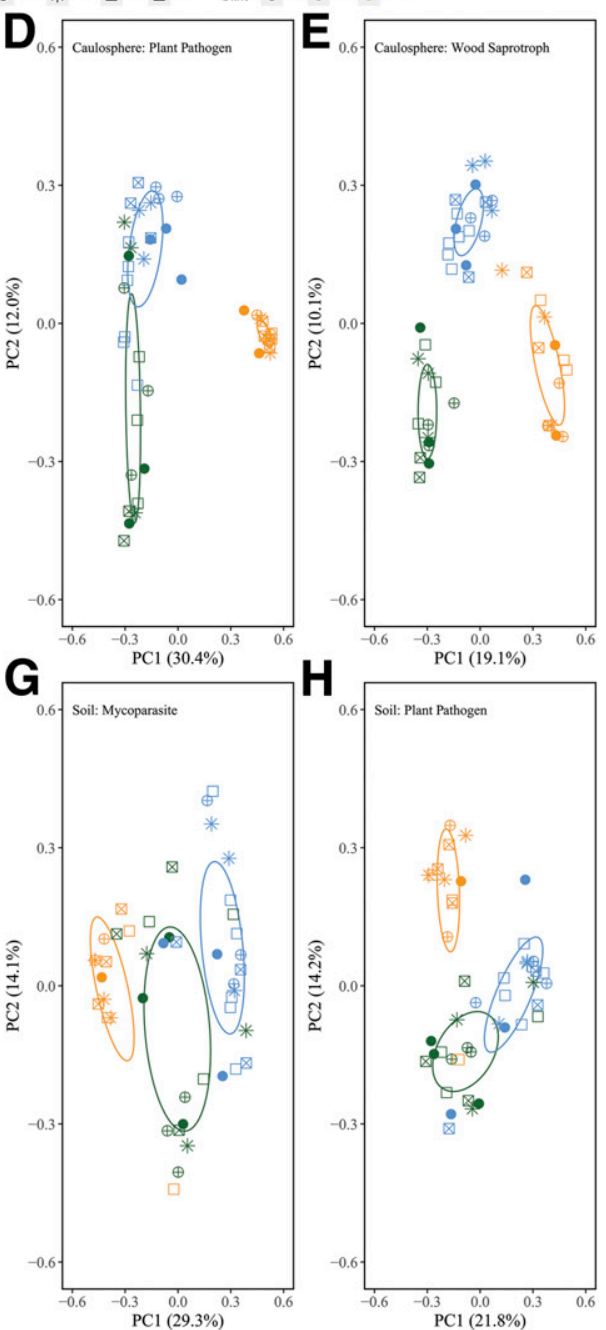

Fig. 4. Relative abundance of $\mathbf{A}$, caulosphere and $\mathbf{B}$, soil fungal functional guilds from Juglans nigra trees in Indiana (IN), Tennessee (TN), and Washington (WA). Principal coordinate (PC) analyses of caulosphere $\mathbf{C}$, mycoparasite; D, plant pathogen; and $\mathbf{E}$, wood saprotroph communities and soil F, arbuscular mycorrhizae; G, mycoparasite; and $\mathbf{H}$, plant pathogen communities from IN, TN, and WA. Fungal functional guilds were assigned to fungal operational taxonomic units (OTUs) using the FUNGuild database (accessed 26 November 2019). In caulosphere fungal communities, 632 of 1,578 OTUs were assigned to a fungal functional guild. In soil fungal communities, 3,836 of 6,738 OTUs were assigned to a fungal functional guild. 
invasion success, which may be dependent upon more than just the $\alpha$-diversity of recipient communities but also the phylogenetic relatedness of the invader to its recipient plant communities and the spatial scale under consideration (Fitzgerald et al. 2016; Li et al. 2015).

In addition to potentially limiting the establishment success of G. morbida, species-rich microbial communities tend to be more complex and possess greater multifunctionality and functional redundancy than species-poor communities (Wagg et al. 2014, 2019). We observed the highest levels of network complexity in the Washington J. nigra caulosphere compared with Indiana and Tennessee, despite lower levels of species richness in Washington caulosphere communities. The higher levels of network complexity in the Washington caulosphere could be derived from the presence of two stable community states in Washington, one of which contains G. morbida (Fig. 6). Perturbation of the system by G. morbida infection may have pushed the system from one state to the other (Shaw et al. 2019). The hub OTUs in the subnetwork with G. morbida also contained four bacterial OTUs (0007, 0011, 0014, and 0087) identified as indicator species that were present at the TCD-positive site in Knox County and could be involved in disease (Figs. 5A and 7). The Tennessee caulosphere also contains two subnetworks but they segregated between clones and WT trees along with TCD status (Fig. 7). The Tennessee subnetwork associated with WT trees was abundant in clones and WT trees in Indiana (Fig. 7, blue) but the subnetwork associated with Tennessee clones was not well represented in Indiana (Fig. 7, black). However, two bacterial OTUs (0010 and 0031) from the presumably healthy (i.e., G. morbida-free) Washington subnetwork were present in all three states (Fig. 7, red) along with Botu0011 from the G. morbidaassociated Washington subnetwork (Fig. 7, orange).

Compositional differences identified between Indiana and Tennessee communities in this study demonstrate that the J. nigra phytobiome is highly variable across the host's native range. Even

TABLE 3

Results of statistical tests comparing $\alpha$ - and $\beta$-diversity of the Juglans nigra fungal functional guilds ${ }^{\mathrm{a}}$

\begin{tabular}{|c|c|c|c|c|c|c|c|c|c|c|}
\hline \multirow[b]{2}{*}{ Habitat, organism, analysis } & \multicolumn{6}{|c|}{ Richness } & \multicolumn{4}{|c|}{$\begin{array}{c}\beta \text {-Diversity } \\
\text { PERMANOVA }\end{array}$} \\
\hline & $F$ & $d f$ & $P$ & TN-IN & WA-IN & $\overline{\text { WA-TN }}$ & $F^{\mathrm{b}}$ & $d f$ & $P$ & $R^{2}$ \\
\hline \multicolumn{11}{|l|}{ Mycoparasites } \\
\hline State & 31.4 & 2,43 & $<0.001$ & 0.861 & $<0.001$ & $<0.001$ & 16.5 & 2,43 & $<0.001$ & 0.43 \\
\hline State $\times$ clone & 0.8 & 8,31 & 0.610 & $\ldots$ & $\ldots$ & $\ldots$ & 1.3 & 8,31 & 0.144 & 0.12 \\
\hline \multicolumn{11}{|l|}{ Plant pathogens } \\
\hline State & 6.2 & 2,43 & 0.004 & 0.289 & 0.159 & 0.003 & $15.1^{c}$ & 2,39 & $<0.001$ & 0.40 \\
\hline Clone & 0.5 & 4,39 & 0.730 & $\ldots$ & $\ldots$ & $\ldots$ & $1.63^{\mathrm{c}}$ & 4,39 & 0.033 & 0.09 \\
\hline State $\times$ clone & 1.7 & 8,31 & 0.136 & $\ldots$ & $\ldots$ & $\ldots$ & 1.3 & 8,31 & 0.098 & 0.13 \\
\hline State $\times$ clone & 0.6 & 8,31 & 0.789 & $\ldots$ & $\ldots$ & $\ldots$ & 1.2 & 8,31 & 0.114 & 0.14 \\
\hline \multicolumn{11}{|l|}{ Soil } \\
\hline \multicolumn{11}{|l|}{ Arbuscular mycorrhizae } \\
\hline State & 7.2 & 2,42 & 0.002 & 0.915 & 0.003 & 0.006 & 3.6 & 2,42 & $<0.001$ & 0.15 \\
\hline Clone & 0.6 & 4,38 & 0.680 & $\ldots$ & $\ldots$ & $\ldots$ & 0.9 & 4,38 & 0.742 & 0.07 \\
\hline State $\times$ clone & 1.7 & 8,30 & 0.133 & $\ldots$ & $\ldots$ & $\ldots$ & 1.1 & 8,30 & 0.200 & 0.18 \\
\hline \multicolumn{11}{|l|}{ Mycoparasite } \\
\hline State & 6.1 & 2,42 & 0.005 & 0.080 & 0.004 & 0.312 & 7.9 & 2,42 & $<0.001$ & 0.27 \\
\hline Clone & 0.9 & 4,38 & 0.493 & $\ldots$ & $\ldots$ & $\ldots$ & 1.1 & 4,38 & 0.381 & 0.07 \\
\hline
\end{tabular}

a Unless otherwise stated, significant main effects for state (significant $P$ values in bold) were tested using a one-way analysis of variance (ANOVA), nonsignificant effects for clone were tested in a noninteractive two-way ANOVA, and nonsignificant interactions were tested in a full two-way model. $\mathrm{HSD}=$ honestly significant difference, PERMANOVA = permutational analysis of variance, $\mathrm{TN}=$ Tennessee, IN = Indiana, and WA = Washington . b Pseudo- $F$ statistic.

${ }^{\text {c }}$ Results for state and clone presented from noninteractive two-way model. 
though the Tennessee and Washington caulospheres were characterized by the presence of two subnetworks and higher complexity than Indiana, the caulosphere phytobiomes sampled in the native range (Indiana and Tennessee) shared more taxa with one another than they did with Washington phytobiomes. Despite similarity in subnetwork structure to Tennessee, community membership in Washington was dominated by taxa that were either not present or less abundant in the native range. Geographic
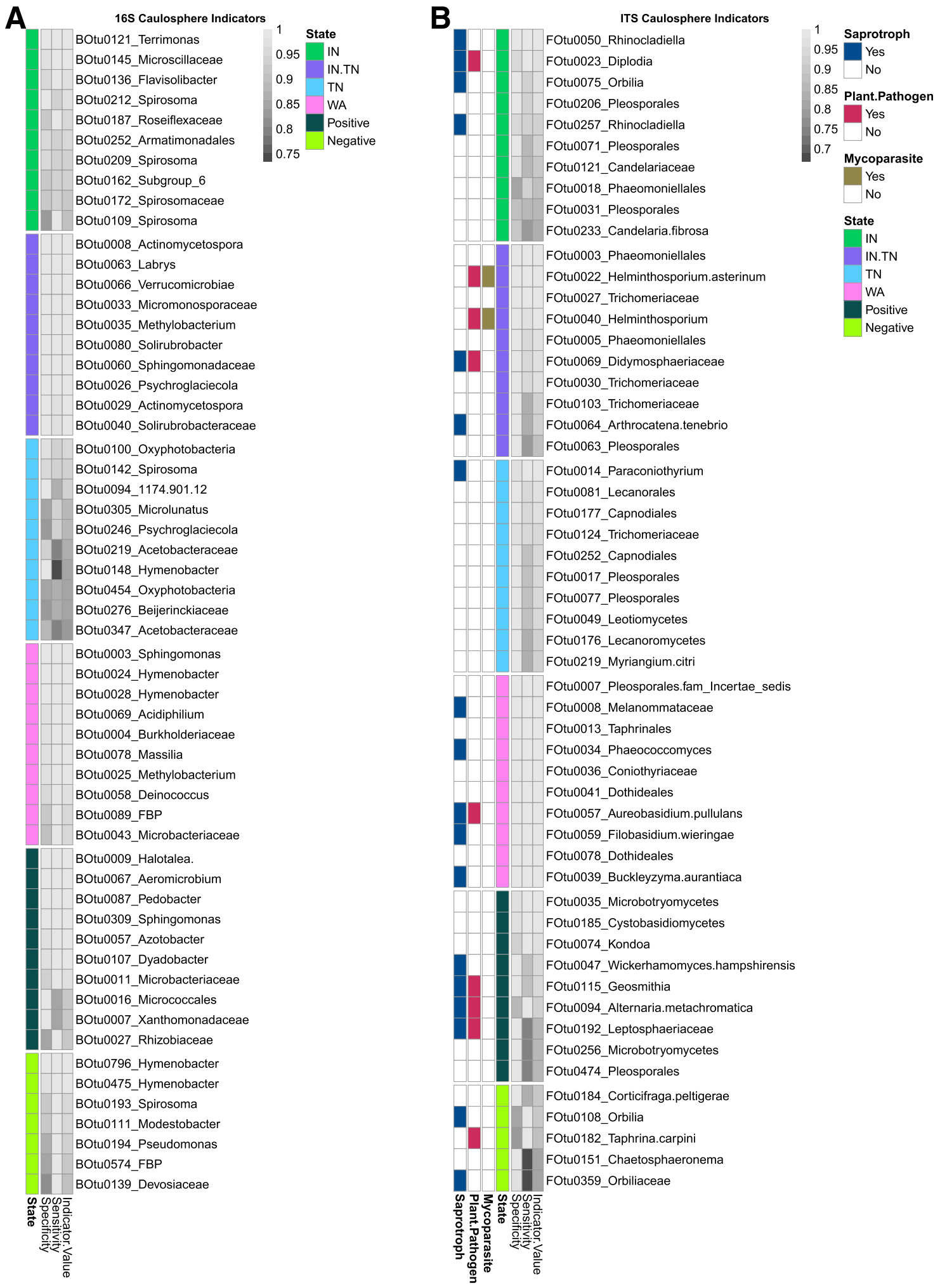

Fig. 5. Sensitivity, specificity, and indicator values for top 10 A, bacterial and B, fungal indicator operational taxonomic units (OTUs) for caulosphere of Juglans nigra in Indiana (IN), Tennessee (TN), Washington (WA), and IN + TN; and thousand cankers disease (TCD)-positive trees and TCD-negative trees in WA. ITS = internal transcribed spacer. Only the top 10 OTUs classified to at least the class level for each group are depicted. The full list of indicator species can be found in Supplementary Table S7. The left three columns indicate whether the OTU was assigned to the saprotroph, plant pathogen, or mycoparasite functional guilds in the FUNGuild database (accessed 26 November 2019). 
variation in the phytobiome among populations of individual species is well documented (Agler et al. 2016; Lu-Irving et al. 2019; Ramirez et al. 2019). Variation among regions has been attributed to differences in associated host plant communities, climate and soil differences, and host genetics (Bálint et al. 2013, 2015; Gundale et al. 2016; Laforest-Lapointe et al. 2016; Ramirez et al. 2019; Wagner et al. 2016). The composition of fungal communities in the caulosphere of J. nigra clones was influenced by host genetics but the bacterial community composition was not. Our observations build on previous reports that fungal communities may be more sensitive to host plant genetics than bacterial communities (Bergelson et al. 2019).

The mycoparasite and plant pathogen communities that were recovered in the native range of J. nigra differed from those found in the introduced range. This observation provides support for the hypothesis that J. nigra has encountered novel pathogens or lacks certain mutualists in its introduced western U.S. range. The greater richness of mycoparasites in the caulosphere of trees in their native range raises the possibility that trees in the native range (Indiana and Tennessee) benefit from direct antagonism of pathogens (Gazis et al. 2018).
Caulosphere fungal communities in both the native and introduced ranges sampled in this study were dominated by sequences classified to the phylum Ascomycota, which aligns with many studies evaluating phyllosphere endophyte communities (Cregger et al. 2018; Rogers et al. 2018). Caulosphere fungal communities in the introduced range of J. nigra (Washington) had a greater proportion of sequences identified to the classes Dothideomycetes and Taphrinomycetes, which contain well-known plant pathogens such as Alternaria spp. (Belisario et al. 1999) and Taphrina spp. (Cissé et al. 2013); the former was identified as an indicator OTU of TCDpositive trees in Washington. Fungi in these taxa could act as secondary pathogens that increase severity of TCD in the western United States (Busby et al. 2016). The class Eurotiomycetes, predominantly represented by Phaeomoniellales, had greater representation in Indiana and Tennessee (Figs. 3C and 5B; Supplementary Fig. S4C). Phaemoniellales is dominated by endophytes of gymnosperms and pathogens of dicots (Chen et al. 2015). Future effort should be undertaken to articulate the roles of these fungi as potential antagonists to G. morbida. Finally, we detected Sydowia polyspora, a common bark beetle associate, as an indicator OTU in the Washington caulosphere (Muñoz-Adalia et al. 2017).
A

IN Caulosphere

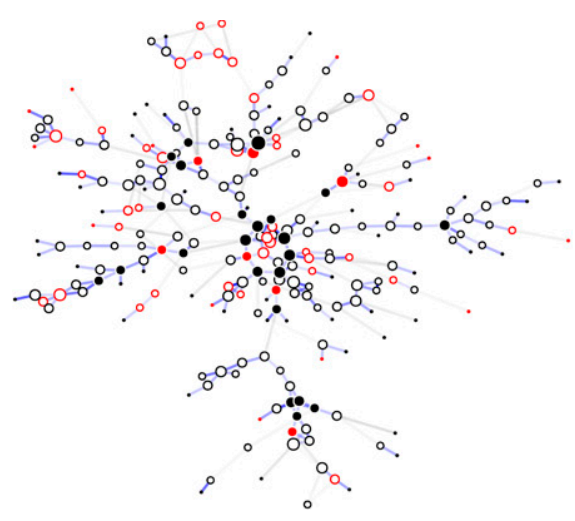

D

IN Soil

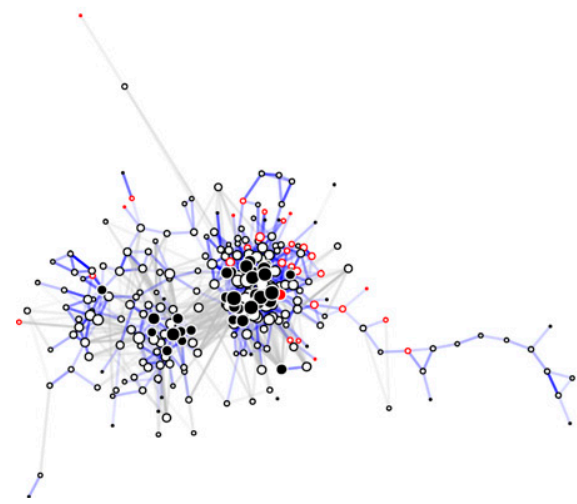

B

TN Caulosphere
C

\section{WA Caulosphere}

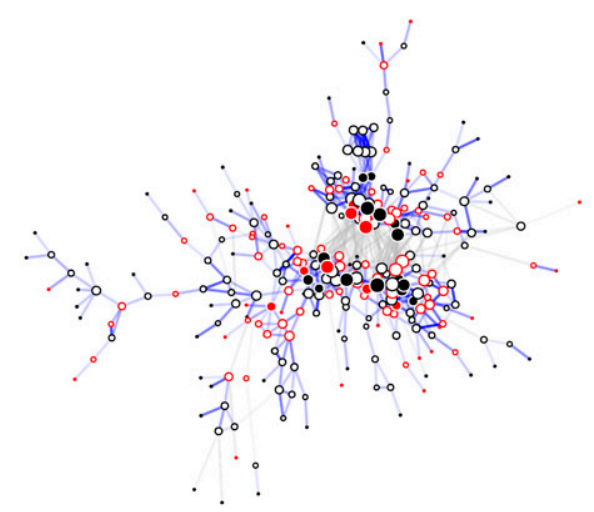

E

TN Soil

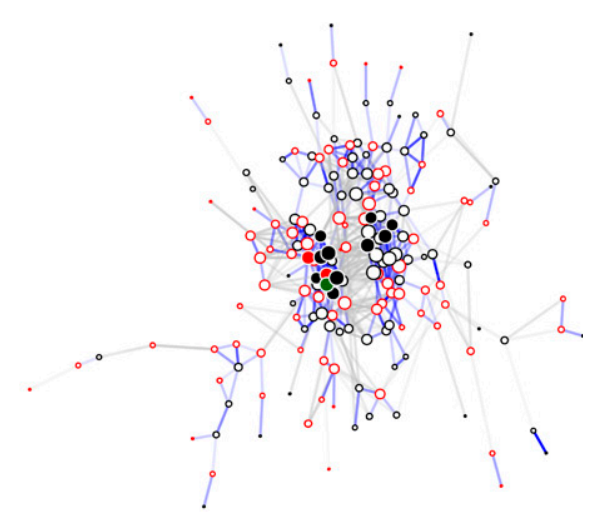

$\mathbf{F}$

WA Soil
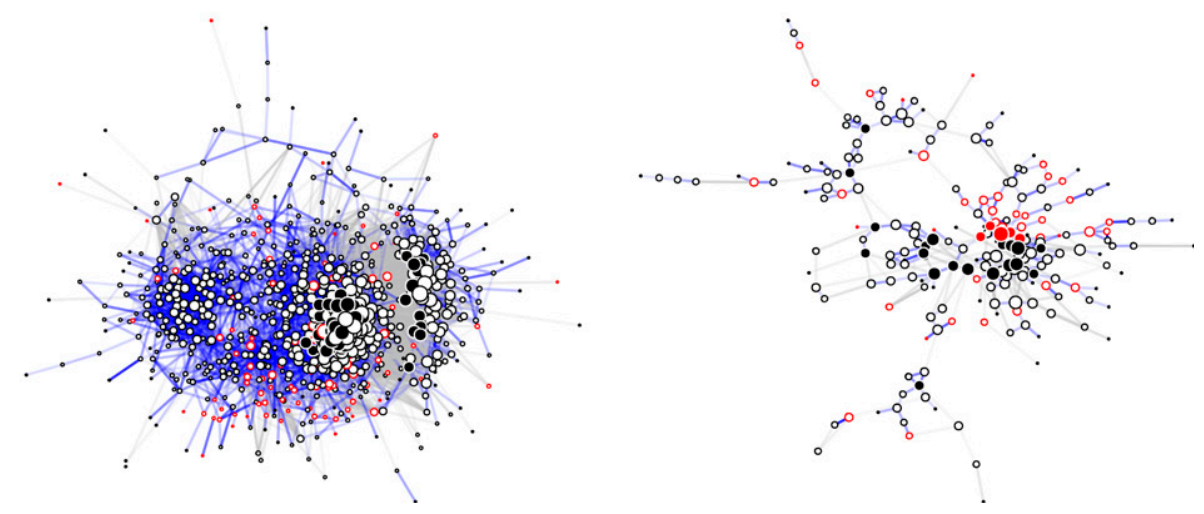

Fig. 6. Depiction of correlation network for relationships among bacterial (black) and fungal (red) operational taxonomic units (OTUs) from the A, B, and C, caulosphere and D, E, and F, soil microbiome of Juglans nigra in Indiana (IN) (A and D), Tennessee (TN) (B and E), and Washington (WA) (C and F), with hub nodes indicated by solid circles and Geosmithia morbida as a green circle (C). Size of node indicates number of connections (degree). Darkness of lines indicates strength of correlation (absolute value of Spearman coefficient $>0.8$ ). $P$ value cutoffs for networks shown are $<0.01$ for caulosphere (A, B, and C) and $<10^{-5}$ for soil (D, E, and F). Positive and negative associations are indicated by blue and gray lines, respectively. Independent subnetworks not shown. 
Interestingly, we did not detect any Trichoderma OTUs in the caulosphere despite their prevalence among fungi that were cultured from insect-induced galleries and fungal lesions (Gazis et al. 2018). Failure to detect Trichoderma could be a product of primer bias which limited the amplification of Trichoderma DNA (Tedersoo and Lindahl 2016), extraction bias, or the fact that sampling in this study did not include the insect galleries themselves. It is also possible that Trichoderma spp. were not present in the samples. These results highlight the importance of using culture-dependent methods in tandem with culture-independent screening to provide a more complete picture of microbial communities that are interacting with infected host plants (Goulart et al. 2019; Pei et al. 2017; Weber et al. 2019).

Caulosphere bacterial communities were dominated by sequences from the phylum Proteobacteria and did not contain archaeal sequences consistent with observations of other hardwood and coniferous tree species (Cregger et al. 2018; Proença et al. 2017; Ren et al. 2019; Rogers et al. 2018). OTUs belonging to $\beta$-Proteobacteriales ( $\gamma$-Proteobacteria) were more abundant in Washington than the native range, and mainly classified to Burkholderiaceae, which were also identified as indicator OTUs for the Washington caulosphere. Burkholderiaceae are considered to be ruderal species because they thrive in low-stress, highly disturbed environments and are reported as plant pathogens and endophytes (Bulgari et al. 2012; Fierer 2017; Kajiwara 2016). Additionally, members of the Burkholderiaceae family are commonly detected in culture-dependent and cultureindependent assessments of bark beetles and bark beetle galleries (Cardoza et al. 2009; Mason et al. 2015). The higher relative abundance of Burkholderiaceae in Washington may be related to higher levels of disease incidence in this region.

Both soil $\alpha$-diversity and community composition differed between native and introduced ranges of J. nigra. However, withinrange differences were less distinct in the soil compared with the caulosphere, suggesting that different factors drive community composition in caulosphere and soil environments. Compared with bulk soil, communities directly associated with plant tissues are more strongly influenced by host biology and exclusionary interactions occurring in response to other endophytes (Lagunas et al. 2015; Newcombe et al. 2018; Plett and Martin 2018; Roy and Kirchner 2000). In soils, microbial communities are structured in large part by dispersal and edaphic factors (Colin et al. 2017; Erlandson et al. 2018; Fierer 2017; Fukami 2015; Glassman et al. 2017). In support of this, the stress-tolerant groups Acidobacteria, Chloroflexi, and Verrucomicrobia were most common in the most
Otu0309 Sphaceloma Botu0094 Beijerinckiaceae

Botu0148 Hymenobacter

Botu0388 Beijerinckiaceae Otu0203 Strelitziana

Botu0035 Methylobacterium

Botu0253 Roseomonas

Botu0356 Acidobacteriaceae

Otu0595 Ascomycota

Botu0210 Beijerinckiaceae

Otu0324 Paraphoma

Botu0074 Sphingomonadaceae

Botu0488 Beijerinckiaceae

Otu0019 Ascomycota

Otu0089 Phaeophyscia

Otu0253 Lecanoromycetes

Otu0037 Caliciopsis

Botu0170 Actinobacteria

Botu0274 Gemmatirosa

Botu0119 Spirosoma

Botu0071 Spirosoma

Botu0592 Chthoniobacter

Botu0316 Ktedonobacteria

Otu0032 Phaeosphaeriaceae

Botu0087 Pedobacter

Botu0007 Xanthomonadaceae

Botu0014 Rhizobiaceae

Otu0118 Knufia

Botu0011 Microbacteriaceae

Botu0047 Luteimonas

Botu0067 Aeromicrobium

Otu0115 Geosmithia

Botu0031 Hymenobacter

Botu0058 Deinococcus

Botu0010 Friedmanniella

Botu0475 Hymenobacter

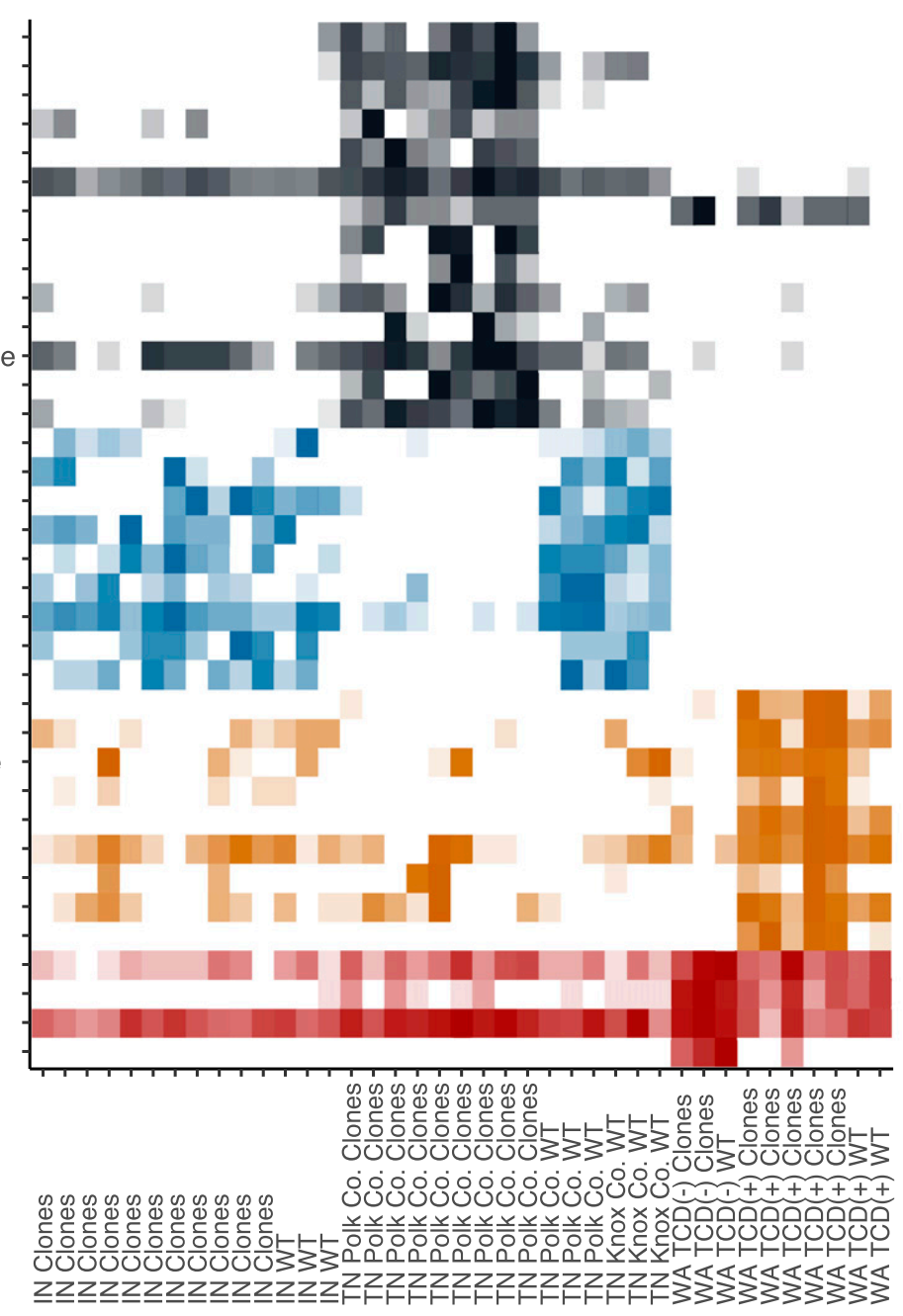

\section{Tennessee}

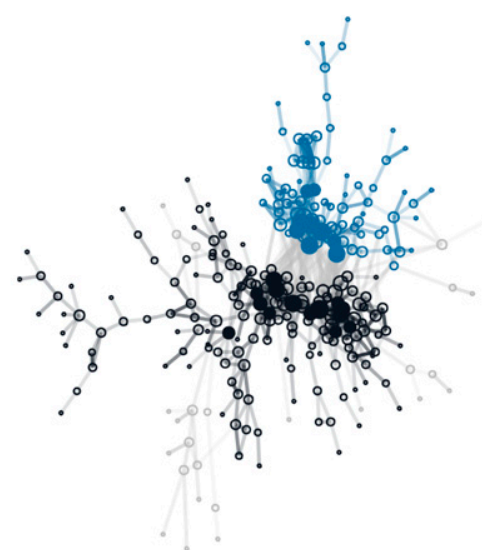

Washington

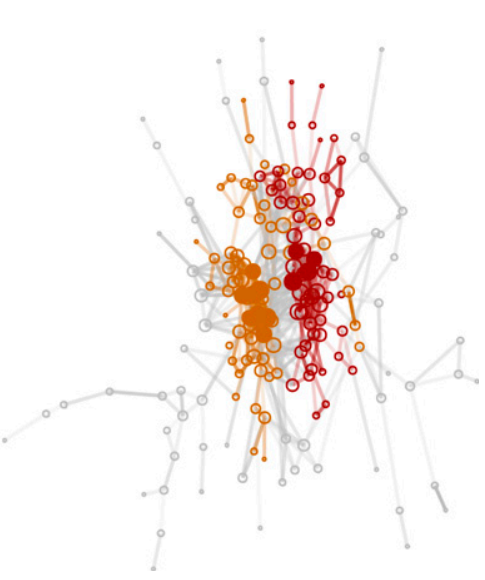

Fig. 7. Heatmap of the relative abundance of hub taxa from alternative highlighted subnetworks of Juglans nigra in Tennessee (TN) (black and blue) and Washington (WA) (orange and red) caulosphere microbiome from merged fungal and bacterial data. WT = wild type. Darkness of squares in the heatmap represents standardized log transformed abundance of each operational taxonomic unit. Size of nodes indicates number of connections (degree), hub nodes are depicted as solid circles, darkness of lines indicates absolute value of Spearman's $r(>0.8)$, and networks are based on associations with $P<0.01$. 
highly weathered soils in Tennessee, followed by Indiana (Fierer 2017). Soil physicochemical properties significantly differed between sites, most likely due to differences in soil type and land use history between sites. Higher $\alpha$-diversity in the bacterial soil communities was likely driven by higher $\mathrm{pH}$ and lower $\mathrm{NO}_{3} \cdot \mathrm{N}$ concentrations in Washington soils compared with Indiana and Tennessee soils (Campbell et al. 2010; Zhang et al. 2017). Lower fungal richness in Washington soils compared with Indiana and Tennessee soils could be attributed to differences in the relative ability of native fungal communities to adapt to novel substrates or allelochemicals such as the root-secreted juglone (Block et al. 2019; Ladino-Orjuela et al. 2016; Lubbers et al. 2019; Meinhardt and Gehring 2012; Schmidt 1988).

There were significant differences in the community composition of arbuscular mycorrhizae in the soil within the native and introduced ranges of J. nigra. Arbuscular mycorrhizal richness was also greater in Indiana and Tennessee. Arbuscular mycorrhizae are important plant symbionts that suppress canker diseases of apple (Krishna et al. 2010) and poplar (Tang and Chen 1994) and, thus, may contribute to the observed differences in TCD severity. To better understand differences in arbuscular mycorrhizal communities between the native and introduced ranges of J. nigra, future studies should evaluate and compare root colonization by arbuscular mycorrhizae.

We also detected significant differences in the composition of plant pathogens in soil communities between the native and introduced ranges of $J$. nigra. In particular, the pathogens Fusarium redolens and Alternaria spp. were identified as indicator OTUs in Washington soils. The presence of $F$. redolens in Washington soils is of interest due to previous studies which found coinfection of G. morbida and Fusarium solani in J. nigra trees (Montecchio et al. 2015; Tisserat et al. 2009). Fusarium redolens is a pathogen of chickpea (JiménezFernández et al. 2011) and wheat (Esmaeili Taheri et al. 2011; Moya-Elizondo et al. 2011) in the Pacific Northwest. These two crops are among the most common rotation crops that are planted in southeast Washington, where our study site is located. Gibberella zeae, a common pathogen of wheat, was also detected as an indicator OTU of TCD-positive trees, providing further support to the idea that land-use history may explain some of the observed differences in soil microbiota associating with $J$. nigra trees. We also detected Clonostachys spp. as indicator OTUs in the soils of Indiana + Tennessee and TCD-negative trees in Washington; this common mycoparasitic biocontrol fungus can induce systemic acquired resistance in plant hosts, suggesting a possible role in suppression of TCD (Roberti et al. 2008; Rodríguez et al. 2011).

In additional to regional differences, host genetics influenced fungal community composition in the caulosphere of J. nigra trees in this study. Given evidence that host genetics also play a significant role in regulating the severity of TCD infections and the higher severity and incidence of TCD in urban habitats, future efforts to develop practical management approaches for TCD should consider host genetic, environmental, and management factors that could modify susceptibility to disease (Busby et al. 2017).

Conclusion. In this study, we found evidence that genetic and geographic factors lead to differences in the richness, diversity, and composition of the $J$. nigra microbiome across the host's native and introduced ranges. These differences could possibly have a role in the observed geographical differences in TCD severity and incidence; however, additional research employing manipulated controlled experiments is needed to disentangle the effects of disease and geography on the phytobiome and the role of the phytobiome in controlling TCD spread (Busby et al. 2016). It should be noted that the microbiome can provide only a partial explanation for differences in TCD incidence and severity. WTB and G. morbida have likely not yet been introduced to north-central Indiana due to successful quarantine protections, thus explaining the absence of these TCD members in our Indiana study location. Differences in prevailing climate are also likely to be important factors that limit the establishment of both the fungus and its vector, accounting for differences in disease incidence and severity between the native and introduced ranges of J. nigra.

\section{ACKNOWLEDGMENTS}

We thank the HTIRC, D. Warwick (Tree Improvement Forester, Tennessee Division of Forestry), J. Conn (Reforestation Unit Leader, Tennessee Division of Forestry, East Tennessee Nursery), B. Rupar, B. and R. Nelson, F. Coronado in Walla Walla, WA, and J. McKenna (U.S. Forest Service) in Indiana for their assistance, background knowledge, and sampling access to wild-type trees and trees in the clonal walnut plantations; and G. Pietsch (the University of Tennessee), B. Kapoor, B. Sallee-Thomas, T. Stewart, M. Ethington, and C. Knell for providing technical field support.

\section{LITERATURE CITED}

Agler, M. T., Ruhe, J., Kroll, S., Morhenn, C., Kim, S.-T., Weigel, D., and Kemen, E. M. 2016. Microbial hub taxa link host and abiotic factors to plant microbiome variation. PLoS Biol. 14:e1002352.

Arrieta, A., Díaz, B., and Frutos, D. 2010. Exploration and selection of walnut genotypes (Juglans regia L.) in Asturias with potential tolerance to Xanthomonas arborícola pv. Juglandis (Xaj). Span. J. Rural Dev. 1:1-6.

Bálint, M., Bartha, L., O’Hara, R. B., Olson, M. S., Otte, J., Pfenninger, M., Robertson, A. L., Tiffin, P., and Schmitt, I. 2015. Relocation, high-latitude warming and host genetic identity shape the foliar fungal microbiome of poplars. Mol. Ecol. 24:235-248.

Bálint, M., Tiffin, P., Hallström, B., O’Hara, R. B., Olson, M. S., Fankhauser, J. D., Piepenbring, M., and Schmitt, I. 2013. Host genotype shapes the foliar fungal microbiome of balsam poplar (Populus balsamifera). PLoS One 8: e53987.

Barberán, A., Bates, S. T., Casamayor, E. O., and Fierer, N. 2012. Using network analysis to explore co-occurrence patterns in soil microbial communities. ISME J. 6:343-351.

Belisario, A., Forti, E., Corazza, L., and Van Kesteren, H. 1999. First report of Alternaria alternata causing leaf spot on English walnut. Plant Dis. 83:696.

Bergelson, J., Mittelstrass, J., and Horton, M. W. 2019. Characterizing both bacteria and fungi improves understanding of the Arabidopsis root microbiome. Sci. Rep. 9:24.

Block, A. K., Yakubova, E., and Widhalm, J. R. 2019. Specialized naphthoquinones present in Impatiens glandulifera nectaries inhibit the growth of fungal nectar microbes. Plant Direct 3:e0132.

Blood, B. L., Klingeman, W. E., Paschen, M. A., Hadžiabdić, Đ., Couture, J. J., and Ginzel, M. D. 2018. Behavioral responses of Pityophthorus juglandis (Coleoptera: Curculionidae: Scolytinae) to volatiles of black walnut and Geosmithia morbida (Ascomycota: Hypocreales: Bionectriaceae), the causal agent of thousand cankers disease. Environ. Entomol. 47:412-421.

Bonchev, D., and Buck, G. A. 2005. Quantitative measures of network complexity. Pages 191-235 in: Complexity in Chemistry, Biology, and Ecology. Springer, New York.

Bright, D. E. 1981. Taxonomic monograph of the genus Pityophthorus Eichhoff in North and Central America (Coleoptera: Scolytidae). Mem. Entomol. Soc. Can. 113:1-378.

Bulgari, D., Bozkurt, A. I., Casati, P., Çağlayan, K., Quaglino, F., and Bianco, P. A. 2012. Endophytic bacterial community living in roots of healthy and 'Candidatus Phytoplasma mali'-infected apple (Malus domestica, Borkh.) trees. Antonie Leeuwenhoek 102:677-687.

Busby, P. E., Ridout, M., and Newcombe, G. 2016. Fungal endophytes: Modifiers of plant disease. Plant Mol. Biol. 90:645-655.

Busby, P. E., Soman, C., Wagner, M. R., Friesen, M. L., Kremer, J., Bennett, A., Morsy, M., Eisen, J. A., Leach, J. E., and Dangl, J. L. 2017. Research priorities for harnessing plant microbiomes in sustainable agriculture. PLoS Biol. 15:e2001793. 
Campbell, B. J., Polson, S. W., Hanson, T. E., Mack, M. C., and Schuur, E. A. 2010. The effect of nutrient deposition on bacterial communities in Arctic tundra soil. Environ. Microbiol. 12:1842-1854.

Cardoza, Y. J., Vasanthakumar, A., Suazo, A., and Raffa, K. F. 2009. Survey and phylogenetic analysis of culturable microbes in the oral secretions of three bark beetle species. Entomol. Exp. Appl. 131:138-147.

Chen, K.-H., Miadlikowska, J., Molnár, K., Arnold, A. E., U’Ren, J. M., Gaya, E., Gueidan, C., and Lutzoni, F. 2015. Phylogenetic analyses of eurotiomycetous endophytes reveal their close affinities to Chaetothyriales, Eurotiales, and a new order-Phaeomoniellales. Mol. Phylogenet. Evol. 85: 117-130.

Cissé, O. H., Almeida, J. M., Fonseca, Á., Kumar, A. A., Salojärvi, J., Overmyer, K., Hauser, P. M., and Pagni, M. 2013. Genome sequencing of the plant pathogen Taphrina deformans, the causal agent of peach leaf curl. MBio 4: e00055-13.

Colin, Y., Nicolitch, O., Van Nostrand, J. D., Zhou, J. Z., Turpault, M. P., and Uroz, S. 2017. Taxonomic and functional shifts in the beech rhizosphere microbiome across a natural soil toposequence. Sci. Rep. 7:9604.

Cregger, M., Veach, A., Yang, Z., Crouch, M., Vilgalys, R., Tuskan, G., and Schadt, C. 2018. The Populus holobiont: Dissecting the effects of plant niches and genotype on the microbiome. Microbiome 6:31.

De Caceres, M., and Jansen, F. 2016. indicspecies: Relationship between species and groups of sites. Page Functions to assess the strength and statistical significance of the relationship between species occurrence/abundance and groups of sites. https://cran.r-project.org/web/packages/indicspecies/ index.html

De Caceres, M., Jansen, F., and Dell, N. 2020. Package 'indicspecies'. https:// vegmod.github.io/software/indicspecies

Erlandson, S., Wei, X., Savage, J., Cavender-Bares, J., and Peay, K. 2018. Soil abiotic variables are more important than Salicaceae phylogeny or habitat specialization in determining soil microbial community structure. Mol. Ecol. 27:2007-2024

Esmaeili Taheri, A., Hamel, C., Gan, Y., and Vujanovic, V. 2011. First report of Fusarium redolens from Saskatchewan and its comparative pathogenicity. Can. J. Plant Pathol. 33:559-564.

Feeley, T. 2010. Emerging threats to Iowa's forests, communities, wood industry, and economy. Thousand cankers disease. Iowa Department of Natural Resources Forestry Bureau.

Fierer, N. 2017. Embracing the unknown: Disentangling the complexities of the soil microbiome. Nat. Rev. Microbiol. 15:579-590.

Fitzgerald, D. B., Tobler, M., and Winemiller, K. O. 2016. From richer to poorer: Successful invasion by freshwater fishes depends on species richness of donor and recipient basins. Glob. Change Biol. 22:2440-2450.

Fox, J., Weisberg, S., Price, B., Adler, D., Bates, D., Baud-Bovy, G., Bolker, B., and Ellison, S. 2018. car: Companion to applied regression. The CRAN R Project. https://cran.r-project.org/web/packages/car/index.html

Fukami, T. 2015. Historical contingency in community assembly: Integrating niches, species pools, and priority effects. Annu. Rev. Ecol. Evol. Syst. 46:1-23.

Gauvrit, N., Singmann, H., Soler-Toscano, F., and Zenil, H. 2016. Algorithmic complexity for psychology: A user-friendly implementation of the coding theorem method. Behav. Res. Methods 48:314-329.

Gazis, R., Poplawski, L., Klingeman, W., Boggess, S. L., Trigiano, R. N., Graves, A. D., Seybold, S. J., and Hadziabdic, D. 2018. Mycobiota associated with insect galleries in walnut with thousand cankers disease reveals a potential natural enemy against Geosmithia morbida. Fungal Biol. 122: 241-253.

Glassman, S. I., Wang, I. J., and Bruns, T. D. 2017. Environmental filtering by $\mathrm{pH}$ and soil nutrients drives community assembly in fungi at fine spatial scales. Mol. Ecol. 26:6960-6973.

Goulart, M. C., Cueva-Yesquén, L. G., Hidalgo Martinez, K. J., Attili-Angelis, D., and Fantinatti-Garboggini, F. 2019. Comparison of specific endophytic bacterial communities in different developmental stages of Passiflora incarnata using culture-dependent and culture-independent analysis. MicrobiologyOpen 8:e896.

Grant, J. F., Windham, M. T., Haun, W. G., Wiggins, G. J., and Lambdin, P. L. 2011. Initial assessment of thousand cankers disease on black walnut, Juglans nigra, in eastern Tennessee. Forests 2:741-748.

Griffin, G. 2015. Status of thousand cankers disease on eastern black walnut in the eastern United States at two locations over 3 years. For. Pathol. 45: 203-214.

Gundale, M. J., Almeida, J. P., Wallander, H., Wardle, D. A., Kardol, P., Nilsson, M. C., Fajardo, A., Pauchard, A., Peltzer, D. A., and Ruotsalainen, S. 2016. Differences in endophyte communities of introduced trees depend on the phylogenetic relatedness of the receiving forest. J. Ecol. 104:1219-1232.
Hadziabdic, D., Vito, L. M., Windham, M. T., Pscheidt, J. W., Trigiano, R. N., and Kolarik, M. 2014a. Genetic differentiation and spatial structure of Geosmithia morbida, the causal agent of thousand cankers disease in black walnut (Juglans nigra). Curr. Genet. 60:75-87.

Hadziabdic, D., Windham, M., Baird, R., Vito, L., Cheng, Q., Grant, J., Lambdin, P., Wiggins, G., Windham, A., and Merten, P. J. P. 2014b. First report of Geosmithia morbida in North Carolina: The pathogen involved in thousand cankers disease of black walnut. Plant Dis. 98:992.

Hoffman, M. T., and Arnold, A. E. 2008. Geographic locality and host identity shape fungal endophyte communities in cupressaceous trees. Mycol. Res. 112:331-344.

Jiménez-Fernández, D., Navas-Cortés, J. A., Montes-Borrego, M., JiménezDíaz, R. M., and Landa, B. B. 2011. Molecular and pathogenic characterization of Fusarium redolens, a new causal agent of Fusarium yellows in chickpea. Plant Dis. 95:860-870.

Juzwik, J., Banik, M. T., Reed, S. E., English, J. T., and Ginzel, M. D. 2015. Geosmithia morbida found on weevil species Stenomimus pallidus in Indiana. Plant Health Prog. 16:7-10.

Juzwik, J., McDermott-Kubeczko, M., Stewart, T., and Ginzel, M. 2016. First report of Geosmithia morbida on ambrosia beetles emerged from thousand cankers-diseased Juglans nigra in Ohio. Plant Dis. 100:1238.

Kajiwara, H. 2016. Direct detection of the plant pathogens Burkholderia glumae, Burkholderia gladioli pv. gladioli, and Erwinia chrysanthemi pv. zeae in infected rice seedlings using matrix assisted laser desorption/ionization timeof-flight mass spectrometry. J. Microbiol. Methods 120:1-5.

Kim, J., and Wilhelm, T. 2008. What is a complex graph? Physica A. 387:2637-2652.

Klironomos, J. N. 2002. Feedback with soil biota contributes to plant rarity and invasiveness in communities. Nature 417:67-70.

Knops, J. M., Tilman, D., Haddad, N. M., Naeem, S., Mitchell, C. E., Haarstad, J., Ritchie, M. E., Howe, K. M., Reich, P. B., and Siemann, E. 1999. Effects of plant species richness on invasion dynamics, disease outbreaks, insect abundances and diversity. Ecol. Lett. 2:286-293.

Koskella, B., Meaden, S., Crowther, W. J., Leimu, R., and Metcalf, C. J. E. 2017. A signature of tree health? Shifts in the microbiome and the ecological drivers of horse chestnut bleeding canker disease. New Phytol. 215:737-746.

Kozich, J. J., Westcott, S. L., Baxter, N. T., Highlander, S. K., and Schloss, P. D. 2013. Development of a dual-index sequencing strategy and curation pipeline for analyzing amplicon sequence data on the MiSeq Illumina sequencing platform. Appl. Environ. Microbiol. 79:5112-5120.

Krishna, H., Das, B., Attri, B. L., Grover, M., and Ahmed, N. 2010. Suppression of Botryosphaeria canker of apple by arbuscular mycorrhizal fungi. Crop Prot. 29:1049-1054.

Ladino-Orjuela, G., Gomes, E., da Silva, R., Salt, C., and Parsons, J. R. 2016. Metabolic pathways for degradation of aromatic hydrocarbons by bacteria. Pages 105-121 in: Reviews of Environmental Contamination and Toxicology (Continuation of Residue Reviews), Vol. 237. W. P. de Voogt, ed. Springer, Cham, Switzerland.

Laforest-Lapointe, I., Messier, C., and Kembel, S. W. 2016. Host species identity, site and time drive temperate tree phyllosphere bacterial community structure. Microbiome 4:27.

Lagunas, B., Schäfer, P., and Gifford, M. 2015. Housing helpful invaders: The evolutionary and molecular architecture underlying plant root-mutualist microbe interactions. J. Exp. Bot. 66:2177-2186.

Li, S., Cadotte, M. W., Meiners, S. J., Hua, Z., Shu, H. y., Li, J., and Shu, W. 2015. The effects of phylogenetic relatedness on invasion success and impact: Deconstructing Darwin's naturalisation conundrum. Ecol. Lett. 18: 1285-1292.

Lu-Irving, P., Harenčár, J. G., Sounart, H., Welles, S. R., Swope, S. M., Baltrus, D. A., and Dlugosch, K. M. 2019. Native and invading yellow starthistle (Centaurea solstitialis) microbiomes differ in composition and diversity of bacteria. MSphere 4:e00088-19.

Lubbers, R. J., Dilokpimol, A., Visser, J., Mäkelä, M. R., Hildén, K. S., and de Vries, R. P. 2019. A comparison between the homocyclic aromatic metabolic pathways from plant-derived compounds by bacteria and fungi. Biotechnol. Adv. 37:107396.

Marshall, P. 2015. Walnut twig beetle detected in Indiana. Indiana Department of Natural Resources.

Mason, C. J., Hanshew, A. S., and Raffa, K. F. 2015. Contributions by host trees and insect activity to bacterial communities in Dendroctonus valens (Coleoptera: Curculionidae) galleries, and their high overlap with other microbial assemblages of bark beetles. Environ. Entomol. 45:348-356.

Meinhardt, K. A., and Gehring, C. A. 2012. Disrupting mycorrhizal mutualisms: A potential mechanism by which exotic tamarisk outcompetes native cottonwoods. Ecol. Appl. 22:532-549. 
Montecchio, L., Faccoli, M., Short, D. P. G., Fanchin, G., Geiser, D. M., and Kasson, M. T. 2015. First report of Fusarium solani phylogenetic species 25 associated with early stages of thousand cankers disease on Juglans nigra and Juglans regia in Italy. Plant Dis. 99:1183.

Moore, M., Juzwik, J., Miller, F., Roberts, L., and Ginzel, M. D. 2019. Detection of Geosmithia morbida on numerous insect species in four eastern states. Plant Health Prog. 20:133-139.

Moricca, S., Bracalini, M., Benigno, A., Ginetti, B., Pelleri, F., and Panzavolta, T. 2019. Thousand cankers disease caused by Geosmithia morbida and its insect vector Pityophthorus juglandis first reported on Juglans nigra in Tuscany, Central Italy. Plant Dis. 103:369.

Mowshowitz, A. 1968. Entropy and the complexity of graphs: II. The information content of digraphs and infinite graphs. Bull. Math. Biophys. 30: 225-240.

Moya-Elizondo, E. A., Rew, L. J., Jacobsen, B. J., Hogg, A. C., and Dyer, A. T. 2011. Distribution and prevalence of Fusarium crown rot and common root rot pathogens of wheat in Montana. Plant Dis. 95:1099-1108.

Mueller, L. A., Kugler, K. G., Dander, A., Graber, A., and Dehmer, M. 2011. QuACN: An R package for analyzing complex biological networks quantitatively. Bioinformatics 27:140-141.

Muñoz-Adalia, E. J., Sanz-Ros, A. V., Flores-Pacheco, J. A., Hantula, J., Diez, J. J., Vainio, E. J., and Fernández, M. 2017. Sydowia polyspora dominates fungal communities carried by two Tomicus species in pine plantations threatened by Fusarium circinatum. Forests 8:127.

Newcombe, G., Harding, A., Ridout, M., and Busby, P. E. 2018. A hypothetical bottleneck in the plant microbiome. Front. Microbiol. 9:1645.

Nguyen, N. H., Song, Z., Bates, S. T., Branco, S., Tedersoo, L., Menke, J., Schilling, J. S., and Kennedy, P. G. 2016. FUNGuild: An open annotation tool for parsing fungal community datasets by ecological guild. Fungal Ecol. 20: 241-248

Nilsson, R. H., Larsson, K.-H., Taylor, A. F. S., Bengtsson-Palme, J., Jeppesen, T. S., Schigel, D., Kennedy, P., Picard, K., Glöckner, F. O., and Tedersoo, L. 2019. The UNITE database for molecular identification of fungi: Handling dark taxa and parallel taxonomic classifications. Nucleic Acids Res. 47: D259-D264.

Oksanen, J., Blanchet, F. G., Friendly, M., Kindt, R., Legendre, P., McGlinn, D., Minchin, P. R., O’Hara, R. B., Simpson, G. L., Solymos, P., Henry, M., Stevens, H., Szoecs, E., and Maintainer, H. W. 2019. vegan: Community ecology package. https://cran.r-project.org/web/packages/vegan/index.html

Oren, E., Klingeman, W., Gazis, R., Moulton, J., Lambdin, P., Coggeshall, M., Hulcr, J., Seybold, S. J., and Hadziabdic, D. 2018. A novel molecular toolkit for rapid detection of the pathogen and primary vector of thousand cankers disease. PLoS One 13:e0185087.

Paradis, E., and Schliep, K. 2019. ape 5.0: An environment for modern phylogenetics and evolutionary analyses in R. Bioinformatics 35:526-528.

Parker, M. A., Malek, W., and Parker, I. M. 2006. Growth of an invasive legume is symbiont limited in newly occupied habitats. Divers. Distrib. 12:563-571.

Pedersen, T. 2019. tidygraph: A Tidy API for Graph Manipulation. https://cran. r-project.org/web/packages/tidygraph/index.html

Pei, C., Mi, C., Sun, L., Liu, W., Li, O., and Hu, X. 2017. Diversity of endophytic bacteria of Dendrobium officinale based on culture-dependent and cultureindependent methods. Biotechnol. Biotechnol. Equip. 31:112-119.

Pinto, S. M., and Ortega, Y. K. 2016. Native species richness buffers invader impact in undisturbed but not disturbed grassland assemblages. Biol. Invasions 18:3193-3204

Plett, J. M., and Martin, F. M. 2018. Know your enemy, embrace your friend: Using omics to understand how plants respond differently to pathogenic and mutualistic microorganisms. Plant J. 93:729-746.

Prider, J., Watling, J., and Facelli, J. M. 2008. Impacts of a native parasitic plant on an introduced and a native host species: Implications for the control of an invasive weed. Ann. Bot. (Lond.) 103:107-115.

Proença, D. N., Francisco, R., Kublik, S., Schöler, A., Vestergaard, G., Schloter, M., and Morais, P. V. 2017. The microbiome of endophytic, wood colonizing bacteria from pine trees as affected by pine wilt disease. Sci. Rep. 7:4205.

R Core Team. 2018. R: A Language and Environment for Statistical Computing, Vienna, Austria. https://www.R-project.org/

R Core Team. 2019. R: A Language and Environment for Statistical Computing, Vienna, Austria. https://www.R-project.org/

Ramirez, K. S., Snoek, L. B., Koorem, K., Geisen, S., Bloem, L. J., Ten Hooven, F., Kostenko, O., Krigas, N., Manrubia, M., and Caković, D. 2019. Rangeexpansion effects on the belowground plant microbiome. Nat. Ecol. Evol. 3: 604-611.

Ren, F., Kovalchuk, A., Mukrimin, M., Liu, M., Zeng, Z., Ghimire, R. P., Kivimäenpää, M., Holopainen, J. K., Sun, H., and Asiegbu, F. O. 2019.
Tissue microbiome of Norway spruce affected by Heterobasidion-induced wood decay. Microb. Ecol. 77:640-650.

Roberti, R., Veronesi, A., Cesari, A., Cascone, A., Di Berardino, I., Bertini, L., and Caruso, C. 2008. Induction of PR proteins and resistance by the biocontrol agent Clonostachys rosea in wheat plants infected with Fusarium culmorum. Plant Sci. 175:339-347.

Rodríguez, M. A., Cabrera, G., Gozzo, F., Eberlin, M., and Godeas, A. 2011. Clonostachys rosea BAFC3874 as a Sclerotinia sclerotiorum antagonist: Mechanisms involved and potential as a biocontrol agent. J. Appl. Microbiol. 110:1177-1186

Rogers, T. J., Leppanen, C., Brown, V., Fordyce, J. A., LeBude, A., Ranney, T., Simberloff, D., and Cregger, M. A. 2018. Exploring variation in phyllosphere microbial communities across four hemlock species. Ecosphere 9:e02524.

Roy, B., and Kirchner, J. 2000. Evolutionary dynamics of pathogen resistance and tolerance. Evolution 54:51-63.

Rugman-Jones, P. F., Seybold, S. J., Graves, A. D., and Stouthamer, R. 2015. Phylogeography of the walnut twig beetle, Pityophthorus juglandis, the vector of thousand cankers disease in North American walnut trees. PLoS One 10:e0118264.

Schloss, P. D. 2020. Reintroducing mothur: 10 Years later. Appl. Environ Microbiol. 86:e2343-19.

Schmidt, S. 1988. Degradation of juglone by soil bacteria. J. Chem. Ecol. 14:1561-1571.

Seybold, S. J., Klingeman, W. E., III, Hishinuma, S. M., Coleman, T. W., and Graves, A. D. 2019. Status and impact of walnut twig beetle in urban forest, orchard, and native forest ecosystems. J. For. 117:152-163.

Shaw, L. P., Bassam, H., Barnes, C. P., Walker, A. S., Klein, N., and Balloux, F. 2019. Modelling microbiome recovery after antibiotics using a stability landscape framework. ISME J. 13:1845-1856.

Soler-Toscano, F., Zenil, H., Delahaye, J.-P., and Gauvrit, N. 2014. Calculating Kolmogorov complexity from the output frequency distributions of small Turing machines. PLoS One 9:e96223.

Stachowicz, J. J., Whitlatch, R. B., and Osman, R. W. 1999. Species diversity and invasion resistance in a marine ecosystem. Science 286:1577-1579.

Stricker, K. B., Harmon, P. F., Goss, E. M., Clay, K., and Luke Flory, S. 2016. Emergence and accumulation of novel pathogens suppress an invasive species. Ecol. Lett. 19:469-477.

Tang, M., and Chen, D. 1994. The effect of vesicular-arbuscular mycorrhizas on the resistance of poplar to a canker fungus (Dothiorella gregaria). Mycorrhizas Plant. For. Asia 92:67.

Tedersoo, L., Bahram, M., Põlme, S., Kõljalg, U., Yorou, N. S., Wijesundera, R., Ruiz, L. V., Vasco Palacios, A. M., Thu, P. Q., Suija, A., and Smith, M. E. 2014. Global diversity and geography of soil fungi. Science 346:1256688.

Tedersoo, L., and Lindahl, B. 2016. Fungal identification biases in microbiome projects. Environ. Microbiol. Rep. 8:774-779.

Thompson, B. M., Bodart, J., and Gruner, D. S. 2019. Community resistance to an invasive forest insect-fungus mutualism. Ecosphere 10:e02609.

Tisserat, N., Cranshaw, W., Leatherman, D., Utley, C., and Alexander, K. 2009. Black walnut mortality in Colorado caused by the walnut twig beetle and thousand cankers disease. Plant Health Prog. 10:10.

Treiman, T., Atchison, B., McDonnell, T., Barden, C., and Moser, W. K. 2010. Economic loss associated with the introduction of thousand cankers disease of black walnut to Kansas. Kansas Forest Service, Kansas State University Agricultural Experiment Station and Cooperative Extension Service.

Treiman, T., and Tuttle, J. 2009. Thousand cankers disease of black walnut: How much will it hurt Missouri's pocketbook? Notes for Forest Managers, Rep. 16. Missouri Department of Conservation.

Trivedi, P., He, Z., Van Nostrand, J. D., Albrigo, G., Zhou, J., and Wang, N. 2012. Huanglongbing alters the structure and functional diversity of microbial communities associated with citrus rhizosphere. ISME J. 6:363-383.

Utley, C., Nguyen, T., Roubtsova, T., Coggeshall, M., Ford, T. M., Grauke, L., Graves, A. D., Leslie, C. A., McKenna, J., and Woeste, K. 2013. Susceptibility of walnut and hickory species to Geosmithia morbida. Plant Dis. 97:601-607.

van der Putten, W. H., Kowalchuk, G. A., Brinkman, E. P., Doodeman, G. T. A., van der Kaaij, R. M., Kamp, A. F. D., Menting, F. B. J., and Veenendaal, E. M. 2007. Soil feedback of exotic savannah grass relates to pathogen absence and mycorrhizal selectivity. Ecology 88:978-988.

van Elsas, J. D., Chiurazzi, M., Mallon, C. A., Elhottovā, D., Krištůfek, V., and Salles, J. F. 2012. Microbial diversity determines the invasion of soil by a bacterial pathogen. Proc. Natl. Acad. Sci. U.S.A. 109:1159-1164.

Veach, A. M., Morris, R., Yip, D. Z., Yang, Z. K., Engle, N. L., Cregger, M. A., Tschaplinski, T. J., and Schadt, C. W. 2019. Rhizosphere microbiomes diverge among Populus trichocarpa plant-host genotypes and chemotypes, but it depends on soil origin. Microbiome 7:76. 
Wagg, C., Bender, S. F., Widmer, F., and van der Heijden, M. G. 2014. Soil biodiversity and soil community composition determine ecosystem multifunctionality. Proc. Natl. Acad. Sci. U.S.A. 111:5266-5270.

Wagg, C., Schlaeppi, K., Banerjee, S., Kuramae, E. E., and van der Heijden, M. G. 2019. Fungal-bacterial diversity and microbiome complexity predict ecosystem functioning. Nat. Commun. 10:4841.

Wagner, M. R., Lundberg, D. S., Tijana, G., Tringe, S. G., Dangl, J. L., and Mitchell-Olds, T. 2016. Host genotype and age shape the leaf and root microbiomes of a wild perennial plant. Nat. Commun. 7:12151.

Weber, M., Liedtke, J., Plattes, S., and Lipski, A. 2019. Bacterial community composition of biofilms in milking machines of two dairy farms assessed by a combination of culture-dependent and-independent methods. PLoS One 14: e0222238.

Wei, Z., Hu, J., Yin, S., Xu, Y., Jousset, A., Shen, Q., and Friman, V.-P. 2018. Ralstonia solanacearum pathogen disrupts bacterial rhizosphere microbiome during an invasion. Soil Biol. Biochem. 118:8-17.

White, T. J., Bruns, T., Lee, S., and Taylor, J. 1990. Amplification and direct sequencing of fungal ribosomal RNA genes for phylogenetics. Pages 315-322 in: PCR Protocols: A Guide to Methods and Applications. M. A. Innis, D. H. Gelfand, J. J. Sninsky, and T. J. White, eds. Academic Press, San Diego, CA, U.S.A.

Williams, R. D. 1990. Juglans nigra L., black walnut. Silvics North Am. 2: 391-399.
Wood, S. L., and Bright, D. E. 1992. A catalog of Scolytidae and Platypodidae (Coleoptera), Part 2: Taxonomic Index. Volume B. Great Basin Nat. Mem. 13:835-1557.

Zenil, H., Soler-Toscano, F., Delahaye, J.-P., and Gauvrit, N. 2015. Two-dimensional Kolmogorov complexity and an empirical validation of the Coding theorem method by compressibility. PeerJ Comput. Sci. 1: e23.

Zenil, H., Soler-Toscano, F., Dingle, K., and Louis, A. A. 2014. Correlation of automorphism group size and topological properties with program-size complexity evaluations of graphs and complex networks. Phys. A (Amsterdam, Neth.) 404:341-358.

Zerillo, M. M., Ibarra Caballero, J., Woeste, K., Graves, A. D., Hartel, C., Pscheidt, J. W., Tonos, J., Broders, K., Cranshaw, W., Seybold, S. J., and Tisserat, N. 2014. Population structure of Geosmithia morbida, the causal agent of thousand cankers disease of walnut trees in the United States. PLoS One 9:e112847.

Zhang, Q., Yang, R., Tang, J., Yang, H., Hu, S., and Chen, X. 2010. Positive feedback between mycorrhizal fungi and plants influences plant invasion success and resistance to invasion. PLoS One 5:e13280.

Zhang, Y., Shen, H., He, X., Thomas, B. W., Lupwayi, N. Z., Hao, X., Thomas, M. C., and Shi, X. 2017. Fertilization shapes bacterial community structure by alteration of soil pH. Front. Microbiol. 8:1325. 